\section{DISENTANGLING RETICULATE EVOLUTION OF NORTH TEMPERATE HAPLOSTEMONOUS LUDWIGIA (ONAGRACEAE) $)^{1,2}$}

\author{
Shih-Hui Liu, ${ }^{3}$ Hsun-An Yang, ${ }^{4}$ Yoshiko Kono, ${ }^{4}$ \\ Peter C. Hoch, ${ }^{5}$ Janet C. Barber,${ }^{6}$ Ching-I Peng, ${ }^{4 \dagger}$ \\ and Kuo-Fang Chung ${ }^{*}$
}

\begin{abstract}
While it is known that whole genome duplication (WGD) and reticulate evolution play important roles in plant evolution, the origins and evolutionary histories of most polyploid and reticulate groups are still poorly known. The North Temperate haplostemonous (NTH) Ludwigia L. (sections Isnardia (L.) W. L. Wagner \& Hoch, Ludwigia, Microcarpium Munz, and Miquelia P. H. Raven) group, characterized by having 4-merous and haplostemonous flowers, pluriseriate and free seeds, glabrous and convex nectaries, and a north-temperate distribution, is a polyploid complex $(2 \times, 4 \times, 6 \times$, and $8 \times)$ of 24 species with frequent reports of inter- and intrasectional hybridization. Although earlier biosystematics studies postulated some evolutionary scenarios and recent molecular phylogenetic studies have partially tested these propositions, the full history of their reticulate evolution remains puzzling. In this study, we sequenced four chloroplast regions $(r p L 16, r p o B$-trnC, trnL-trnF, and ycf6-psbM) and conducted extensive molecular cloning of the biparentally inherited single-copy nuclear PgiC gene ( 376 clones in total), sampling 23 of the 24 NTH Ludwigia species whose chromosome numbers and ploidy levels were confirmed. Both the chloroplast and PgiC trees include strongly supported sister clades of section Ludwigia (four diploid species) and the "Microcarpium complex" (composed of sections Isnardia, Microcarpium, and Miquelia), which together are sister to the rest of Ludwigia. In the PgiC tree, eight clades are identified within the Microcarpium complex, with four clades including no extant diploid species. Neither sections Isnardia nor Microcarpium are monophyletic, while the monospecific section Miquelia has a hybrid origin. By integrating our phylogenetic trees with previous cytological hypotheses, the reticulate evolution of NTH Ludwigia is disentangled and four to eight extinct diploid species are inferred. Ancestral area reconstruction supports a North American origin of L. ovalis whose current East Asian distribution reflects a relict of the Arcto-Tertiary Geoflora. Based on our results, we propose to synonymize sections Microcarpium and Miquelia under the expanded section Isnardia.

Key words: Aquatic plants, chloroplast phylogeny, chromosome cytology, glucose-6-phosphate isomerase cytosolic (PgiC) gene, hybridization, Ludwigia, Onagraceae, polyploids.
\end{abstract}

Whole genome duplication (WGD) and reticulate evolution are both common and evolutionarily important in the angiosperms (Stebbins, 1971; Arnold, 1997; Levin, 2002; Soltis et al., 2014). The complexity of polyploid taxa and their reticulate evolution has impeded efforts to elucidate the origins and evolutionary relationships of these taxa (Rieseberg \& Willis, 2007; Soltis et al., 2014; Barker et al., 2016). Earlier cytological studies contributed greatly to the understanding of WGD and reticulate evolution in some plant lineages (e.g., Wagner, 1954; Peng, 1983, 1990; Ramamoorthy
\& Zardini, 1987). Molecular phylogenetic analyses have also provided insights into the origins and relationships of some complicated taxa (e.g., Ford \& Gottlieb, 2007; Jiao \& Paterson, 2014). Several recent studies have shown that combining both molecular and cytological analyses provides even better resolution to untangle the evolutionary puzzle in polyploid and/or reticulate groups (Lipman et al., 2013; Mandák et al., 2018).

Ludwigia L., the sole genus in Onagraceae subfamily Ludwigioideae, is an intensively studied polyploid complex comprising 83 predominately wetland species

1 We thank Dr. Peter H. Raven for his continuous support and encouragement to pursue this project and for providing seeds of many North Temperate haplostemonous Ludwigia. Seeds provided by J. A. Abbott, Tsai-Wen Hsu, S. O'Kennon, Anderson, Thompson, Wilbur, Ho, and Les are greatly appreciated. This work was supported by funding from Academia Sinica to Ching-I Peng and Kuo-Fang Chung. Shih-Hui Liu was supported by the Ministry of Science and Technology, Taiwan (MOST 106-2811-B001-108 and MOST 107-2811-B-001-566) postdoctoral fellowship.

2 C.-I. P., K.-F. C., and P. C. H. conceived the study; C.-I. P. and K.-F. C. collected the species from the United States and Taiwan; C.-I. P. took color photographs of the study plants from the wild and the Academia Sinica greenhouse; Y. K. examined the somatic chromosomes; H. A. Y. extracted DNA, amplified the chloroplast regions, and cloned the PgiC region; K.-F. C. and J. C. B. contributed analysis tools; S. H. L. performed phylogenetic analyses and trait evolution analyses; S. H. L. prepared figures and tables, and prepared and archived the sequence data to National Center for Biotechnology Information (NCBI); S. H. L. and K.-F. C. wrote the manuscript; all authors read and approved the final manuscript.

3 Department of Biological Sciences, National Sun-Yet-sen University, Kaohsiung 80424, Taiwan.

4 Research Museum and Herbarium (HAST), Biodiversity Research Center, Academia Sinica, Taipei 11529, Taiwan.

5 Missouri Botanical Garden, 4344 Shaw Blvd., St. Louis, Missouri 63110, U.S.A.

6 Department of Biology, Saint Louis University, St. Louis, Missouri 63103, U.S.A.

* Author for correspondence: bochung@gate.sinica.edu.tw 
with a worldwide distribution (Munz, 1942; Raven, 1963; Eyde, 1977; Raven \& Tai, 1979; Peng, 1983; Wagner et al., 2007; Pesamosca \& Boldrini, 2015; Liu et al., 2017). The North Temperate haplostemonous (NTH) Ludwigia group, characterized by 4-merous and haplostemonous flowers and north-temperate distribution, includes 24 species that have been classified in section Ludwigia, section Isnardia (L.) W. L. Wagner \& Hoch, section Microcarpium Munz, and section Miquelia P. H. Raven (Table 1; Raven, 1963; Wagner et al., 2007). The NTH Ludwigia group is relatively well studied, including analyses on its floral, fruit, and seed anatomy, palynology, embryology, reproductive biology, and cytology (Eyde, 1977, 1978, 1981; Raven, 1979; Raven \& Tai, 1979; Praglowski et al., 1983; Peng \& Tobe, 1987; Peng, 1988, 1989; Tobe et al., 1988; Peng et al., 2005).

Ludwigia sect. Ludwigia (Fig. 1A) includes four diploid species $(2 n=2 \times=16)$, distinguished from other NTH Ludwigia by the combination of alternate leaves, tuberous roots, relatively larger petals, apically dehiscent capsules, and pollen release in tetrads or polyads (Raven \& Tai, 1979; Peng, 1989; Wagner et al., 2007). The other three sections constitute the Microcarpium complex (Eyde, 1981), comprising five diploids, 10 tetraploids ( $2 n=4 \times=32$ ), four hexaploids $(2 n=6 \times=48)$, and one octoploid $(2 n=8 \times=64)$ (Raven \& Tai, 1979; Peng, 1988; Peng et al., 2005). Ludwigia ovalis Miq. (Fig. 1B) of the monospecific section Miquelia is a tetraploid native to East Asia, characterized by alternative leaves, apetalous flowers, irregularly dehiscent capsules, pollen shed in monads, and enlarged seed raphe (Wagner et al., 2007). Ludwigia ovalis is the only NTH Ludwigia not native to America.

Section Isnardia (five species; Fig. 1C-E), previously known as section Dantia Munz, is characterized by having fibrous roots, opposite leaves, apetalous or small-petaled flowers, irregularly dehiscent capsules, and pollen shed in monads or tetrads (Schmidt, 1967; Peng et al., 2005; Wagner et al., 2007). Peng et al. (2005) extensively examined the morphology, geographical distribution, breeding system, and chromosome configuration of section Isnardia, including also cytology and pollen stainability of artificial interspecific hybrids. They reported that the genomes in the section can be identified based on the ability of the chromosomes in the genome to pair as bivalents with chromosomes from other genomes at meiotic metaphase I, shown in their artificial interspecific hybrid experiments. Peng et al. (2005) then identified and hypothesized that four genomes, designated A, B, C, and D (Schmidt, 1967), have been involved in the formation of section Isnardia. The genome of the widely distributed diploid species Ludwigia palustris (L.) Elliott was designated as AA. This species was hypothesized to contribute the A genome to the tetraploid L. spathulata Torr.
\& A. Gray (AADD), following hybridization. The source of the D genome in L. spathulata was not known, however, since there was no extant diploid DD species. Both L. arcuata Walter (BBCC; $4 \times$ ) and L. palustris were hypothesized to contribute to the origins of the hexaploids $L$. repens J. R. Forst. (AABBCC) and $L$. brevipes (Long) Eames (AABBCC). Despite both having the same genomic complement, these two hexaploid species differ in many morphological traits, possibly resulting from independent and/or reciprocal hybridization events (Peng et al., 2005).

Section Microcarpium (14 species; Fig. 1F-I) differs from the other NTH Ludwigia sections by the combination of fibrous roots, alternate leaves, vestigial petalous or apetalous flowers, regularly or irregularly or apically dehiscent capsules, and pollen release in monads or tetrads (Raven \& Tai, 1979; Peng, 1989; Wagner et al., 2007). In their review of the cytology of Ludwigia, Raven and Tai (1979) first proposed hypotheses about the origins of polyploids in this section. Additional systematic, cytological, and experimental hybridization analyses allowed Peng $(1988,1989)$ to refine the work of Raven and Tai (1979). To avoid confusion with genomes A, B, C, and D already assigned to section Isnardia (Schmidt, 1967), Peng (1988) assigned the $\mathrm{F}$ genome to both $L$. linearis Walter (FF; $2 \times$ ) and L. linifolia Poir. (FF; $2 \times$ ) to reflect their morphological and distributional similarity, as well as high seed set, high pollen stainability, and the formation of six to eight bivalents in meiotic metaphase in experimental hybrids (Fig. 2B). Peng (1988) also hypothesized that L. curtissii Chapm. (FFGGHHII; 8×) inherited the $\mathrm{F}$ genome from $L$. linifolia or $L$. linearis, and obtained the $\mathrm{G}, \mathrm{H}$, and I genomes from L. simpsonii Chapm. (GGHHII; 6×). The diploid L. microcarpa Michx. (GG; $2 \times$ ) and unidentified/extinct species with HHII likely contributed genomes to L. simpsonii (Peng, 1988), while the opposite or subopposite leaves near stem bases and a somewhat ascending to prostrate habit in L. simpsonii suggest its affinity with a possibly extinct member of section Isnardia (Peng, 1989). The seven tetraploid species of section Microcarpium (L. glandulosa Walter, L. lanceolata Elliott, L. pilosa Walter, L. polycarpa Short \& R. Peter, L. ravenii C.-I Peng, L. sphaerocarpa Elliott, and L. suffruticosa Walter) are closely related and form what appears to be a homogamic complex (Peng, 1988), but the genomic origins of these tetraploids remain unclear. Here, we assign unidentified genome as " $\mathrm{X}$ " for the latter discussion (i.e., the seven tetraploid species of section Microcarpium are XXXX). Based on its irregular seed surface pattern, Peng (1988) also hypothesized that hybridization between the interfertile tetraploids was responsible for the origin of the highly polymorphic $L$. sphaerocarpa (Fig. 2B). The hexaploid L. alata Elliott (GGXXXX) 


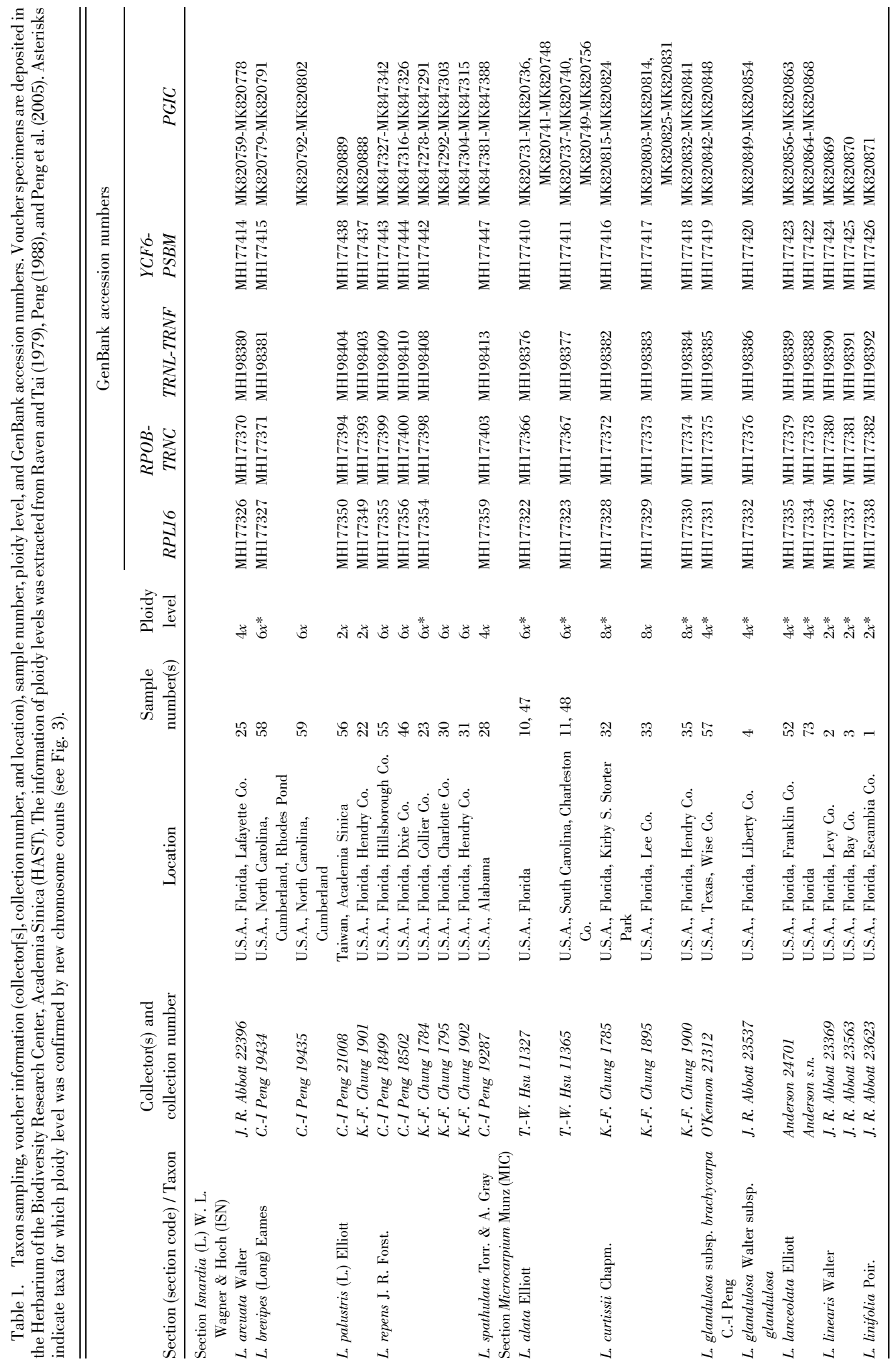




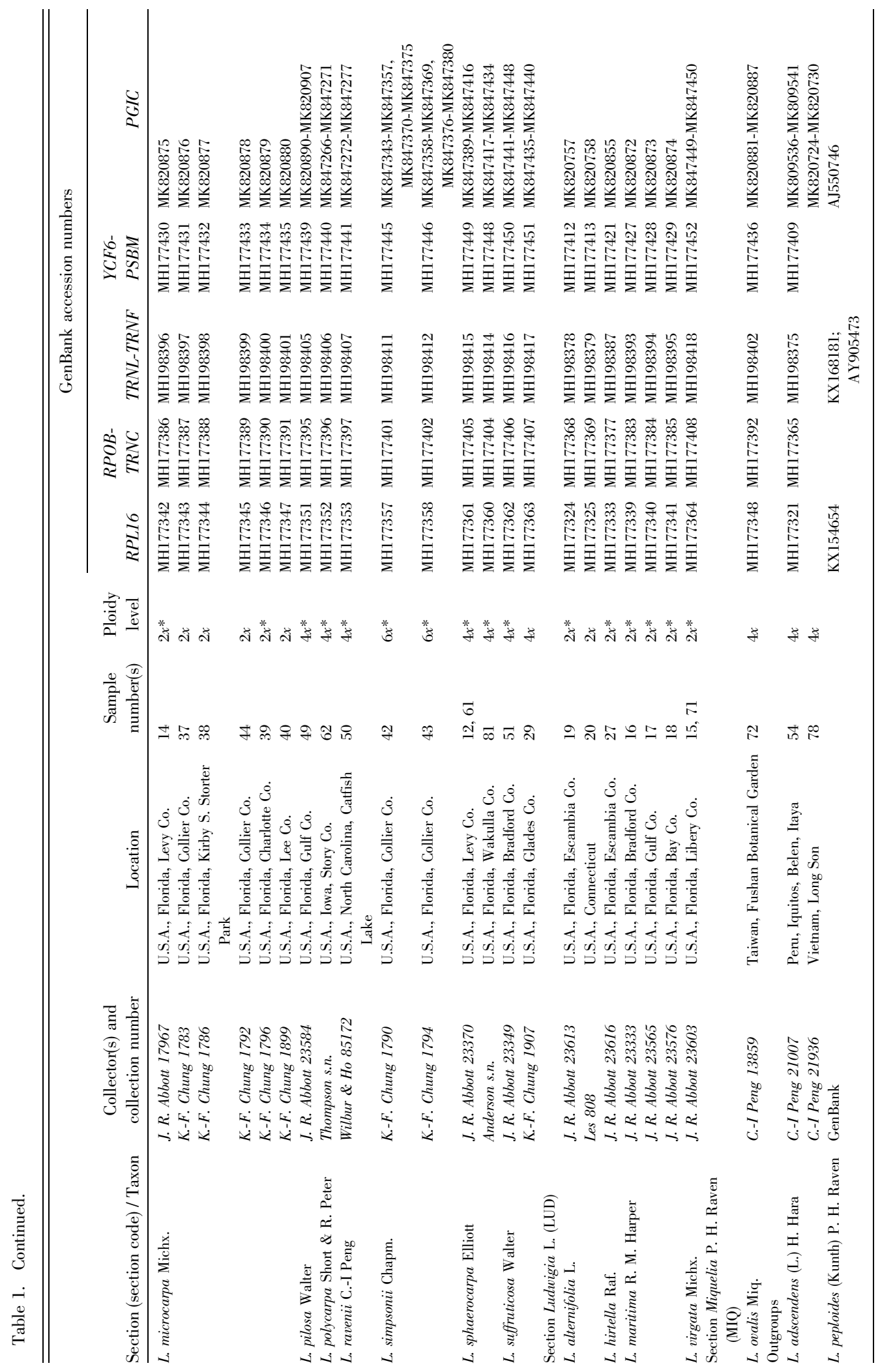



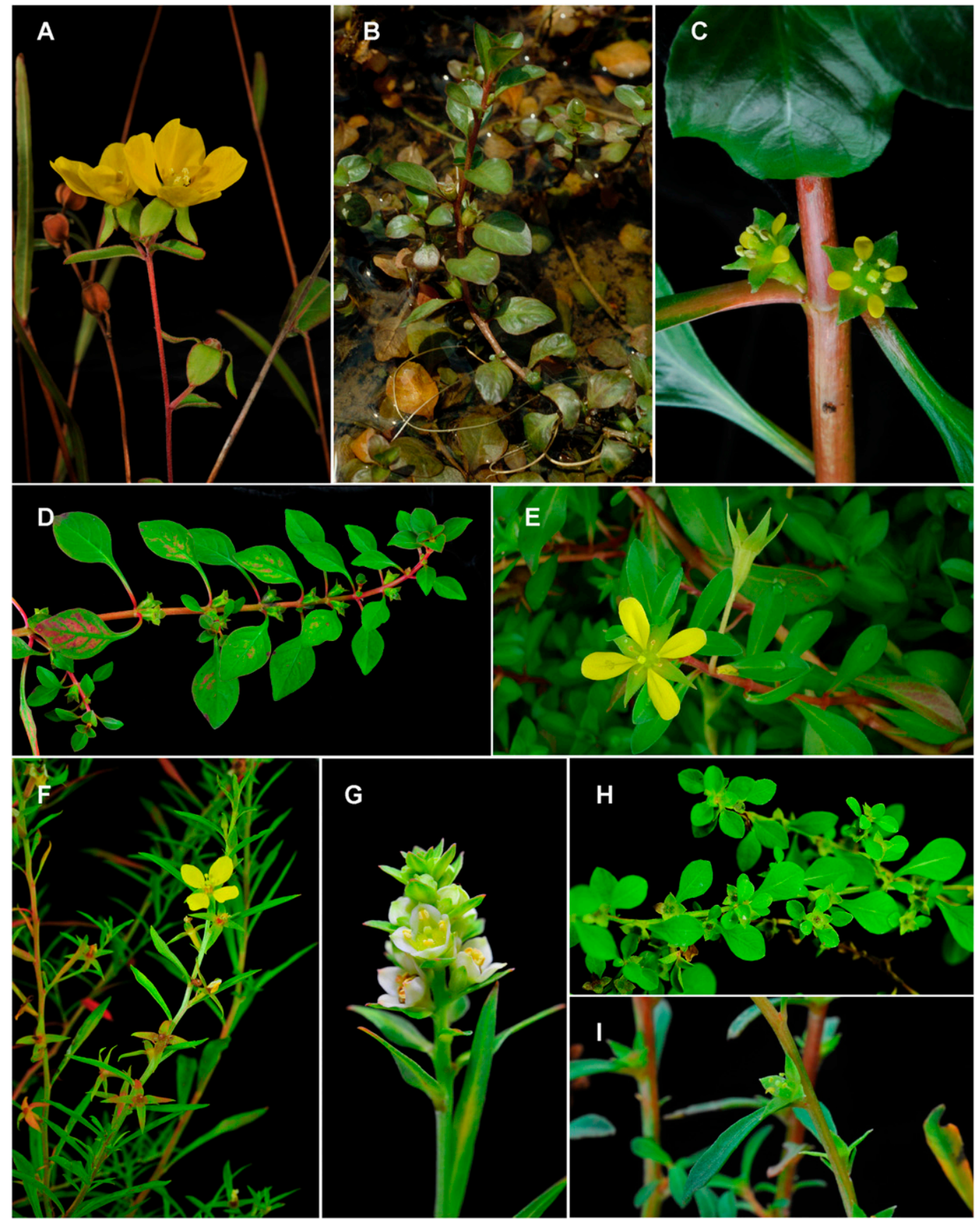

Figure 1. Representatives of the North Temperate haplostemonous Ludwigia L. group. —A. Ludwigia maritima R. M. Harper (section Ludwigia). - B. Ludwigia ovalis Miq. (section Miquelia P. H. Raven). —C. Ludwigia repens J. R. Forst. (section Isnardia (L.) W. L. Wagner \& Hoch). - D. Ludwigia palustris (L.) Elliott (section Isnardia). —E. Ludwigia brevipes (Long) Eames (section Isnardia). -F. Ludwigia linifolia Poir. (section Microcarpium Munz). —G. Ludwigia suffruticosa Walter (section Microcarpium). -H. Ludwigia microcarpa Michx. (section Microcarpium). - I. Ludwigia curtissii Chapm. (section Microcarpium). 


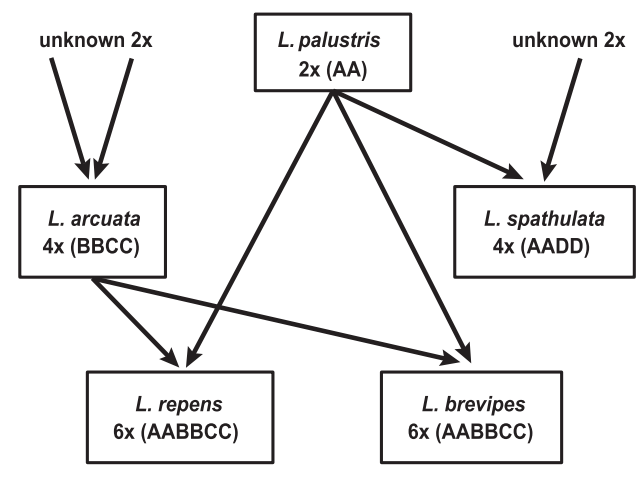

(A)

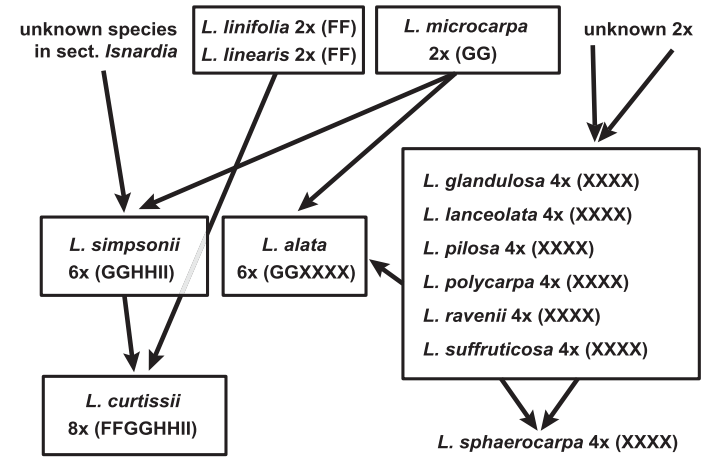

(B)

Figure 2. Hypotheses of the reticulate and polyploid evolution of Ludwigia L. sect. Isnardia (L.) W. L. Wagner \& Hoch (A) and section Microcarpium Munz (B) redrawn based on Peng $(1988,1989)$ and Peng et al. (2005). Note that the genome of $L$. polycarpa Short \& R. Peter was inferred from phylogenies of Liu et al. (2017).

likely resulted from hybridization between $L$. microcarpa (GG) and the tetraploid (XXXX). The Cuban endemic L. stricta (C. Wright ex Griseb.) C. Wright is a diploid closely related to L. linifolia, though its genome has not been characterized. Despite some morphological differences, there is considerable similarity between sections Isnardia and Microcarpium in overall morphology and distributional range (Wagner et al., 2007), with frequent intersectional hybridizations reported (Raven \& Tai, 1979; Peng, 1988, 1989; Peng et al., 2005). Hypotheses of the reticulate evolution of Ludwigia sect. Microcarpium proposed in Peng (1988, 1989) and section Isnardia in Peng et al. (2005) are summarized in Figure 2.

Recent phylogenetic study focused on Ludwigia strongly (chloroplast [cp] DNA) or moderately (nuclear [nr] DNA) supports that section Ludwigia and the Microcarpium complex are sister clades (Liu et al., 2017). Liu et al. (2017) also found that neither section Isnardia nor section Microcarpium is monophyletic. Placement of section Miquelia was unresolved, either within the Isnardia-Microcarpium clade (nrDNA) or sister to it (cpDNA; Liu et al., 2017), suggesting a possible hybrid origin of $L$. ovalis (e.g., Small et al., 2004; Govindarajulu et al., 2015; Gong et al., 2017).

Several phylogenetic studies have tested Peng's hypotheses (Fig. 2) partially (Hung et al., 2009; Hsu, 2010; Liu et al., 2017). Based on cp and ITS sequences, these studies suggested that Ludwigia palustris (AA) contributed as paternal parent to the origin of $L$. spathulata (AADD) and as maternal parent to the origins of L. polycarpa (AAXX) (Liu et al., 2017) and L. brevipes (AABBCC) (Hung et al., 2009). Liu et al. (2017) also suggested that the tetraploid L. polycarpa (section Microcarpium) possesses the A genome (Fig. 2), and that $L$. arcuata $(\mathrm{BBCC})$ is likely the maternal genome donor for $L$. brevipes (AABBCC) and possibly also for $L$. repens (AABBCC) (Hung et al., 2009). Moreover, these analyses verified that $L$. microcarpa $(\mathrm{GG})$ contributed to the origin of L. simpsonii (GGHHII) (Hsu, 2010; Liu et al., 2017), that $L$. simpsonii was a parental donor to $L$. curtissii (FFGGHHII) (Hsu, 2010), and that the tetraploid $L$. lanceolata or $L$. suffruticosa likely contributed to the origin of the hexaploid L. alata (GGXXXX) (Liu et al., 2017). However, none of these studies have sampled adequately to test Peng's hypotheses (Fig. 2; Peng, 1988, 1989; Peng et al., 2005) and completely resolve relationships within the NTH Ludwigia group.

To disentangle the reticulate evolution of the NTH Ludwigia group, we used DNA sequences of the biparentally inherited nuclear single-copy region, PgiC exon11-exon16, and four maternally inherited chloroplast regions (rpL16, rpoB-trnC, trnL-trnF, and $y c f 6-p s b M)$. By integrating our results with earlier biosystematic studies (Peng, 1988, 1989; Peng et al., 2005), evolutionary history of this complicated group is elucidated. Based on our result, we propose to revise the taxonomy of the NTH clade and infer the biogeographic origin of the East Asian species of the NTH Ludwigia.

\section{Materials and Methods}

SAMPLING

We sampled all species of the NTH Ludwigia group except for the Cuban endemic species $L$. stricta, which is very similar to $L$. linifolia (Peng, 1988, 1989). We also sampled two outgroups-L. adscendens (L.) H. Hara and L. peploides (Kunth) P. H. Raven-from the sister clade (clade B in Liu et al., 2017) of the NTH Ludwigia clade to root our phylogeny. Living plants or seeds of most species were collected from natural populations and grown at the Academia Sinica greenhouse. Full voucher 
information is provided in Table 1 . The DNA sequences of $L$. peploides were downloaded from the National Center for Biotechnology Information (NCBI) GenBank.

\section{CHROMOSOME CYTOLOGY}

To confirm species identification and ploidy level, root tips from living plants of the NTH Ludwigia clade (Table 1) at the Academia Sinica greenhouse were examined to count somatic chromosomes. The procedures of chromosome observations followed Kono et al. (2012) and Peng et al. (2014). Root tips were pretreated with $2 \mathrm{mM}$ 8-hydroxyquinoline solution at $15^{\circ}-18^{\circ} \mathrm{C}$ for 6 to 8 hours and then fixed overnight in Carnoy's fluid (95\% ethanol and acetic acid in the ratio of $3: 1$ ) at $4{ }^{\circ} \mathrm{C}$. They were then macerated with an enzyme mixture, including 2\% Cellulase Onozuka R-10 (Yakult Honsha, Tokyo, Japan) and 1\% Pectolyase (Sigma, St. Louis, Missouri, U.S.A.) at $37^{\circ} \mathrm{C}$ for about 1 hour. Root tips were then cut and squashed in $45 \%$ acetic acid. Later, 2\% Giemsa solution (Merck, Darmstadt, Germany) was applied to stained root tips at room temperature for about 10 minutes. Cells at mitotic metaphase were examined and photographed with a Zeiss Axio Imager.A1 (Zeiss, Oberkochen, Germany) and AxioCam $\mathrm{MRm}$ monochrome digital camera (Zeiss).

\section{DNA REGION SELECTION, SEQUENCING, AND CLONING}

Genomic DNA was extracted from fresh leaves of living collections using the DNeasy Plant Mini Kit (Qiagen, Hilden, Germany). Four chloroplast noncoding regions (rpL16, rpoB-trnC, trnL-trnF, and ycf6-psbM) were selected and successfully amplified for all samples. These chloroplast regions have been used in previous phylogenetic studies for various taxa (e.g., Taberlet et al., 1991; Shaw et al., 2005; Chung et al., 2014). For nuclear regions, it is known that multiplecopy regions such as ITS are often unable to resolve polyploid evolution because of their heterozygosity and paralogy (Baldwin et al., 1995; Soltis \& Soltis, 1998; Alvarez \& Wendel, 2003). Here, a single-copy nuclear region, PgiC exon11-exon16, was chosen and applied for all Ludwigia samples.

The $P g i C$ regions have provided insights into the evolutionary histories of plant groups that include polyploids (e.g., Ford \& Gottlieb, 1999; Ford et al., 2006; Juslén et al., 2011), and in particular have elucidated tribal and sectional relationships in Onagraceae (Gottlieb \& Ford, 1996; Ford \& Gottlieb, 2007). Earlier studies revealed that $P g i C$ appears as a single-copy gene in some Onagraceae lineages (e.g., Circaea cordata Royle, Fuchsia cylindracea Lindl., and Hauya heydeana Donn. Sm.), but has two copies in others (e.g., some sections in Clarkia Pursh, Epilobium canum (Greene) P. H. Raven, and E. brachycarpum C. Presl)
(Thomas et al., 1993; Ford \& Gottlieb, 2002, 2007). The copy number of $P g i C$ regions in Ludwigia species was unknown. In this study, we modified the universal primers for PgiC exon11-exon16 region developed by Ford et al. (2006), screened sequences from Ford and Gottlieb's (2007) study, and then replaced some degenerate sites with the DNA bases that are consistent in Onagraceae. Our preliminary results with the modified primers show that $\mathrm{PgiC}$ exon11-exon16 regions of diploid NTH Ludwigia species do not contain a polymorphic site (Supplementary Appendix S1) - that is, diploid NTH Ludwigia species have only one single copy of PgiC exon11-exon16 region. The modified primers are reported in Table 2 .

The polymerase chain reaction (PCR) amplifications were conducted with a mixture of $0.5 \mu \mathrm{L}$ genomic DNA, $1 \mu \mathrm{L}$ forward primer $(10 \mathrm{mM}), 1 \mu \mathrm{L}$ reverse primer (10 mM), $10 \mu \mathrm{L}$ Taq DNA Polymerase Master Mix Red (Ampliqon, Copenhagen, Denmark), and 7.5 $\mathrm{LL}$ deionized water. The optimal thermal cycling conditions for the studied regions are provided in Supplementary Table S1.

The PCR products of the chloroplast regions were purified with the PCR Advanced Clean Up (Viogene BioTek Corp., New Taipei City, Taiwan) and sequenced commercially with the Genomics BioSci \& Tech. Ltd. (New Taipei City, Taiwan). For polyploid Ludwigia samples, the purified PCR products of PgiC region were cloned using the pGEM-T Vector Systems (Promega, Madison, Wisconsin, U.S.A.). Positive colonies were screened using the T7 and SP6 primers and a PCR reaction with our optimal thermal cycling conditions (Supplementary Table S1). Previous hypotheses (Peng, 1988, 1989; Peng et al., 2005) suggested that two genomes were involved in the origin of each tetraploid NTH Ludwigia taxon (Fig. 2). To ascertain the proposition, eight positive clones were sequenced for each tetraploid sample. Similar criteria were applied to other polyploids: 10 to 12 clones were selected for hexaploids, and 16 to 20 clones for octoploids. Selected colonies were purified and sequenced. Contigs were assembled in SeqMan II software 5.0 (DNA Star, Inc., Madison, Wisconsin, U.S.A.). Newly generated sequences have been submitted to GenBank, and accession numbers are reported in Table 1.

\section{PHYLOGENY RECONSTRUCTION}

Sequences were aligned with MAFFT 7 (Katoh et al., 2002; Katoh \& Standley, 2013) and adjusted in Mesquite 3.51 (Maddison \& Maddison, 2018), if needed. Previous study suggests a lack of recombination in Ludwigia plastomes based on genome comparisons (Liu et al., 2017). Hence, in the present study, the alignments of the four chloroplast regions were concatenated for phylogenetic analyses. 
Table 2. Primers used in this study and their origins.

\begin{tabular}{|c|c|c|c|}
\hline DNA region & Primers & Primer sequence $\left(5^{\prime} \rightarrow 3^{\prime}\right)$ & Reference \\
\hline \multirow[t]{2}{*}{$r p L 16$} & $\mathrm{~F}$ & GCTATGCTTAGTGTGTGACTCG & Chung et al. (2014) \\
\hline & $\mathrm{R}$ & CGTCCYGCTTCTATTTGTCTAG & \\
\hline \multirow[t]{2}{*}{ rpoB-trnC } & rpoB & CKACAAAAYCCYTCRAATTG & Shaw et al. (2005) \\
\hline & $\operatorname{trnC}(\mathrm{GCA})-\mathrm{R}$ & CACCCRGATTYGAACTGGGG & \\
\hline \multirow[t]{2}{*}{$\operatorname{trnL-trnF}$} & $\operatorname{trnL5} 5^{\prime}(\mathrm{UAA}) \mathrm{F}(\mathrm{TabC})$ & CGAAATCGGTAGACGCTACG & $\begin{array}{l}\text { Taberlet et al. (1991); Shaw } \\
\text { et al. (2005) }\end{array}$ \\
\hline & $\operatorname{trnF}(\mathrm{GAA})(\mathrm{TabF})$ & ATTTGAACTGGTGACACGAG & \\
\hline \multirow[t]{2}{*}{$y c f 6-p s b M$} & ycf6F & ATGGATATAGTAAGTCTYGCTTGGGC & Shaw et al. (2005) \\
\hline & psbMR & ATGGAAGTAAATATTCTYGCATTTATTGCT & \\
\hline \multirow[t]{2}{*}{ PgiC } & AA $11 F-2$ & TTTGCNTTYTGGGATTGGGT & modified from $P g i C$ universal \\
\hline & AA16R-2 & CCCTTGCCRTTRCTCTCCAT & $\begin{array}{l}\text { primers from Ford et al. } \\
(2006)\end{array}$ \\
\hline
\end{tabular}

Maximum parsimony (MP), maximum likelihood (ML), and Bayesian inference (BI) algorithms were applied for chloroplast and $P g i C$ regions. In MP analyses, 200 searches were conducted in PAUPRat (Sikes \& Lewis, 2001), and a strict consensus tree was generated from the most parsimonious trees for each dataset. To estimate the homoplasies on MP trees, the consistency index (CI) and retention index (RI) were calculated in Mesquite 3.51 (Maddison \& Maddison, 2018) and the rescaled consistency (RC) and homoplasy index (HI) were also computed. The homoplasy and comparative statistics of MP analyses are available in Table 3. The best-fit nucleotide substitution models for chloroplast and $P g i C$ regions were estimated with the Akaike information criterion (AIC) in jModeltest 2.1.8 (Darriba et al., 2012) and then applied in ML and BI trees reconstructions. The best-fit models are shown in Table 3. The ML trees were reconstructed with RAxML 8.2.10 (Stamatakis, 2014) on the CIPRES Science Gateway 3.3 (Miller et al., 2010) with 10 tree searches and 1000 rapid bootstrap (BS) procedures. Bayesian analyses were performed in MrBayes 3.2.6 (Huelsenbeck \& Ronquist, 2001; Ronquist et al., 2012) on the CIPRES Science Gateway 3.3 as well as with two independent Markov chain Monte Carlo (MCMC) runs. Each run began from a random tree and four simultaneous chains set at default temperature (Huelsenbeck \& Ronquist, 2001). Each run was performed for $5 \times 10^{6}$ generations, and one tree was sampled every 1000th generation. The initial $25 \%$ of trees were ignored as burn-in. The remaining trees were summed to generate a $50 \%$ majority rule consensus tree and to estimate the posterior probabilities (PP) on each branch. All trees were viewed with FigTree 1.4.3 (Rambaut, 2014).

\section{BIOGEOGRAPHIC INFERENCE}

To infer the biogeographic origin of Ludwigia ovalis, the only East Asian species of the NTH Ludwigia, we first reconstructed the representative trees based on

Table 3. Comparative statistics for maximum parsimony analyses of the North Temperate haplostemonous Ludwigia L. and the best-fit nucleotide substitution models for the analyzed datasets.

\begin{tabular}{|c|c|c|c|c|c|c|}
\hline $\begin{array}{c}\text { Analyzed } \\
\text { dataset }\end{array}$ & $\begin{array}{l}\text { The best-fit } \\
\text { substitution } \\
\text { models }\end{array}$ & $\begin{array}{c}\text { Number of sequence/ } \\
\text { Ingroup spp. \#/Number of } \\
\text { ingroup sequence/Number of } \\
\text { outgroup sequence }\end{array}$ & $\begin{array}{l}\text { Length in } \\
\text { alignments } \\
\text { (bp) }\end{array}$ & $\begin{array}{l}\text { Number of parsimony } \\
\text { informative characters } \\
\text { (\% of parsimony } \\
\text { informative characters) }\end{array}$ & $\begin{array}{l}\text { Number of } \\
\text { uninformative } \\
\text { variable } \\
\text { characters }\end{array}$ & $\begin{array}{c}\mathrm{CI} / \mathrm{RI} / \mathrm{RC} / \\
\mathrm{HI}\end{array}$ \\
\hline cp tree & $\mathrm{GTR}+\mathrm{I}+\mathrm{G}$ & $45 / 23 / 43 / 2$ & 4371 & $131(3.00 \%)$ & 88 & $\begin{array}{c}0.8604 / \\
0.9454 / \\
0.8134 / \\
0.1396\end{array}$ \\
\hline $\begin{array}{l}\text { PgiC } \\
\text { gene } \\
\text { tree }\end{array}$ & $\mathrm{HKY}+\mathrm{I}+\mathrm{G}$ & $37 / 23 / 362 / 14$ & 1118 & $349(31.22 \%)$ & 200 & $\begin{array}{c}0.6282 / \\
0.9372 / \\
0.5887 / \\
0.3718\end{array}$ \\
\hline
\end{tabular}

CI, consistency index; cp, chloroplast; HI, homoplasy index; RC, rescaled consistency index; RI, retention index. 

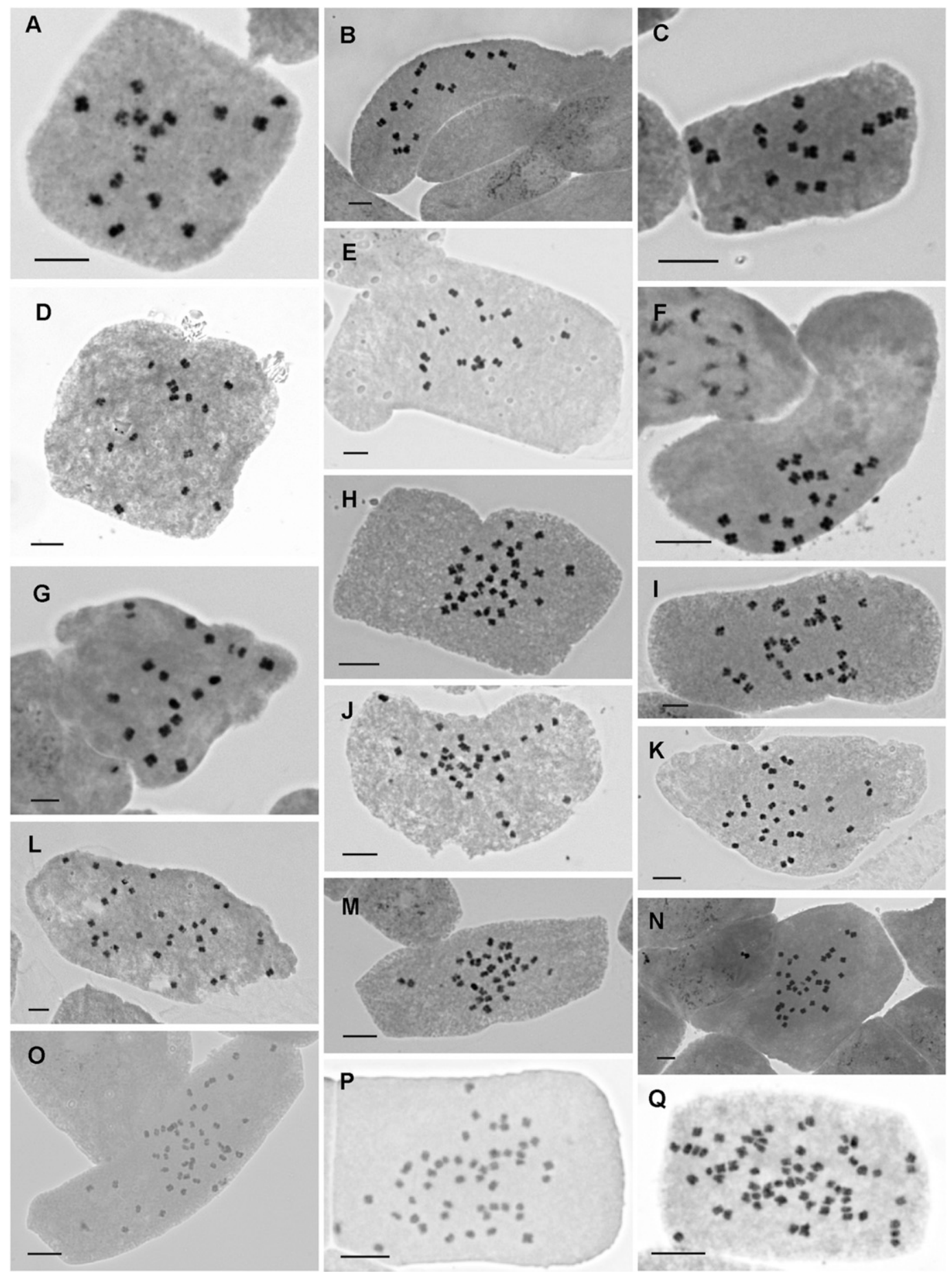

Figure 3. Mitotic chromosomes of selected taxa of the North Temperate haplostemonous Ludwigia L. group. -A. Ludwigia alternifolia L., $2 n=16 .-$ B. Ludwigia hirtella Raf., $2 n=16 .-$ C. Ludwigia maritima R. M. Harper, $2 n=16$. —D. Ludwigia virgata Michx., $2 n=16$. - E. Ludwigia linifolia Poir., $2 n=16 .-$ F. Ludwigia microcarpa Michx., $2 n=16 .-$ G. Ludwigia linearis Walter, $2 n=16$. - H. Ludwigia sphaerocarpa Elliott, $2 n=32$. - I. Ludwigia glandulosa Walter, $2 n=32$. 一J. Ludwigia lanceolata Elliott, $2 n=32$. - K. Ludwigia ravenii C.-I Peng, $2 n=32$. —L. Ludwigia pilosa Walter, $2 n=32$. -M. Ludwigia polycarpa Short \& R. Peter, $2 n=32$. —N. Ludwigia suffruticosa Walter, $2 n=32$. — O. Ludwigia alata Elliott, $2 n=48$. —P. Ludwigia repens J. R. Forst., $2 n=48$. -Q. Ludwigia curtissii Chapm., $2 n=64$. Scale bar $=5 \mu \mathrm{m}$. 
selected $P g i C$ clones representing all genomes of all studied Ludwigia taxa and outgroups. Both ML and BI algorithms described in the previous section (Phylogeny Reconstruction) were applied to generate the representative trees. We defined six geographic areas for biogeographic inferences: (1) North America, (2) South America, (3) Africa, (4) Europe, (5) Asia, and (6) Pacific. The ancestral area was inferred using Mesquite 3.51 (Maddison \& Maddison, 2018). Both the unordered parsimony and likelihood approach with Mkl model were performed. For likelihood analysis, the polymorphic states were treated as uncertain.

\section{Results}

\section{CHROMOSOME CYTOLOGY}

Mitotic chromosomes of the NTH Ludwigia samples are shown in Figure 3, and chromosome numbers are reported in Table 1. Our chromosome counts are consistent with earlier cytological studies of Ludwigia (Raven \& Tai, 1979; Peng, 1988; Peng et al., 2005), supporting our species identification and ploidy determination.

\section{PHYLOGENY RECONSTRUCTION}

For chloroplast regions, our Shimodaira-Hasegawa (SH) tests indicate that the topologies of MP, ML, and BI trees based on the concatenated data set are not inconsistent ( $P$ values $>0.05$ for all pairwise comparisons; Supplementary Table S2). Only the ML tree is shown here (Fig. 4, Supplementary Appendix S2).

Our cp tree shows that section Ludwigia and the Microcarpium complex are both monophyletic (Fig. 4). Within the Microcarpium complex, four clades are present, including $L$. ovalis, clade $\mathrm{A}^{\mathrm{c} p}$, clade $\mathrm{F}^{\mathrm{cp}}$, and clade $\mathrm{G}^{\mathrm{cp}}$ (Fig. 4). The latter three clades are so named based on genome designation (Fig. 2) of the diploid species present in the clade. Ludwigia ovalis is placed with good support values $(\mathrm{PP}=0.92, \mathrm{BS}=91)$ as a branch sister to a clade of sections Isnardia and Microcarpium (clades $A^{c p}+G^{c p}+F^{c p}$ ), neither of which is monophyletic. Because the chloroplast genome is maternally inherited in Onagraceae (Zhang et al., 2003), the $\mathrm{cp}$ tree can be used to infer the maternal genome of the polyploid NTH Ludwigia taxa by comparing with hypotheses outlined in Figure 2.

Clade Fcp is composed of diploid Ludwigia linifolia $(\mathrm{FF})$ and two accessions of $L$. linearis $(\mathrm{FF})$. Clade $\mathrm{A}^{\mathrm{cp}}$ $(\mathrm{PP}=0.99, \mathrm{BS}=100)$ includes the diploid L. palustris (AA) of section Isnardia and all tetraploids of section Microcarpium (XXXX), suggesting that these tetraploids have genome A or a genome closely related to A transmitted from the maternal parent (i.e., AAXX). Of the two accessions sampled for L. sphaerocarpa, J. R. Abbott
$23370(12+61)$ is placed in the same clade with $L$. lanceolata, while Anderson s.n. (81) is placed closer to L. suffruticosa (Fig. 4).

Clade $\mathrm{G}^{\mathrm{cp}}$ includes the diploid Ludwigia microcarpa (GG) of section Microcarpium and all remaining polyploids of the Microcarpium complex. The placement of the tetraploid L. spathulata (AADD) of section Isnardia in clade $G^{\mathrm{cp}}$ suggests that its maternal parent is more closely related to genome $\mathrm{G}$, not genome $\mathrm{A}$. The placement of $L$. arcuata in a well-supported but unresolved clade $(\mathrm{PP}=1.00, \mathrm{BS}=98)$ with the two hexaploids of section Isnardia (i.e., $L$. brevipes [AABBCC] and $L$. repens [AABBCC]) suggests that $L$. arcuata is the maternal parent of the hexaploids, given that those hexaploids were hypothesized to have originated from hybridization (Fig. 2A) between L. palustris (AA) and $L$. arcuata (BBCC). The placement of $L$. alata (GGXXXX) in clade $\mathrm{G}^{\mathrm{cp}}$ also suggests that its $\mathrm{G}$ genome was inherited maternally, given that $L$. alata was hypothesized to have originated through hybridization between L. microcarpa and the tetraploids (XXXX) of section Microcarpium (Fig. 2B). The placement of the hexaploid L. simpsonii (GGHHII) and octoploid $L$. curtissii (FFGGHHII) of section Microcarpium in a strongly supported clade suggests that $L$. simpsonii is the maternal parent of L. curtissii (Fig. 2B). Given Peng's (1989) proposition that section Isnardia likely contributed genomes to $L$. simpsonii, the placement of $L$. curtissii $-L$. simpsonii and $L$. arcuata $-L$. brevipes $-L$. repens in the same clade $(\mathrm{PP}=1.00, \mathrm{BS}=96)$ suggests that the tetraploid $L$. arcuata or a species similar to it might be the maternal parent of $L$. simpsonii (Fig. 2B).

For the $P g i C$ region, a total of 405 positive clones were sequenced. Poorly assembled and obviously artifactual sequences likely resulting from PCR error were removed. Finally, 376 clones representing 23 NTH Ludwigia species (46 samples) and L. adscendens (two samples) were used in this study. The SH tests show that the $\mathrm{ML}$ and $\mathrm{BI}$ trees based on $P g i C$ region are congruent in their topologies ( $P$ value $>0.05$; Supplementary Table S2), whereas the MP tree has a significantly different topology $(P$ values $<0.05$; Supplementary Table S2). The SH test results are not unexpected because both the ML and BI trees were reconstructed using the model algorithms and the MP tree was generated using a nonmodel algorithm. Here, only the ML tree (Supplementary Fig. Sl) is presented.

Our PgiC tree (Supplementary Fig. S1) shows that the clones from each Ludwigia taxon are clustered into the expected number of clades corresponding to their respective ploidy levels except for $L$. sphaerocarpa of which four copies are detected for both accessions (see below). So the clones from a tetraploid are grouped into the two clades; the clones from a hexaploid were grouped into three clades; and the clones from an 


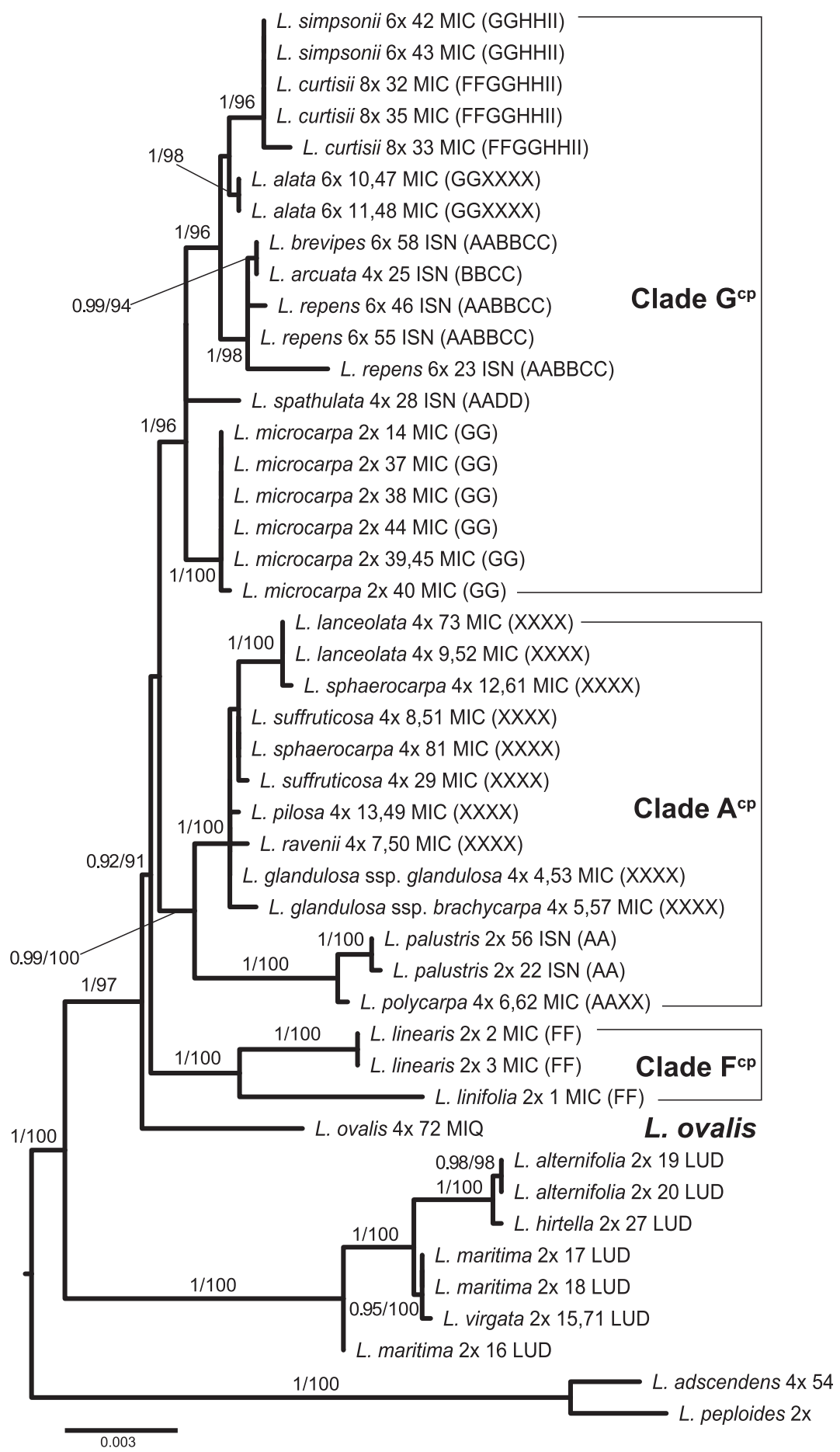

Figure 4. The maximum likelihood tree of North Temperate haplostemonous Ludwigia L. based on four chloroplast regions (rpL16, trnL-trnF, ycf6-psbM, and rpoB-trnC). Numbers on the branches show Bayesian posterior probabilities/bootstrap percentages. Ploidy level, sample number (see Table 1), section code (see Table 1), and genome hypothesized in earlier studies (see Fig. 2) are provided for each sequence. The scale bar indicates the branch length. 
octoploid into four clades. To facilitate the following discussion, all clones (branches) of a genome clade from the same taxa were collapsed. For the cases where clones from two taxa are nested in the same clade, all branches of the nested clade were collapsed into one branch. The collapsed PgiC tree is presented in Figure 5.

The collapsed $P g i C$ tree (Fig. 5) agrees with the cp tree (Fig. 4) in supporting section Ludwigia and the Microcarpium complex as monophyletic sister clades. Within the Microcarpium complex, eight clades are identified with strong branch support values $(\mathrm{PP}=$ 1.00, BS $\geq 75$; Fig. 5); these clades are named A, B/H, $\mathrm{C} / \mathrm{I}, \mathrm{D} / \mathrm{G}, \mathrm{F}_{1}, \mathrm{~F}_{2}, \mathrm{M}_{1}$, and $\mathrm{M}_{2}$ based on presence of the corresponding diploid genome and/or to match with hypotheses of Peng (1988, 1989) and Peng et al. (2005) illustrated in Figure 2. Only clades A, D/G, $\mathrm{F}_{1}$, and $\mathrm{F}_{2}$ include diploid species. Among the eight clades, clades $\mathrm{A}$ and $\mathrm{C} / \mathrm{I}$ are sister groups $(\mathrm{PP}=1.00$, $\mathrm{BS}=82$ ), whereas clades $\mathrm{B} / \mathrm{H}, \mathrm{F}_{1}$, and $\mathrm{F}_{2}$ form a monophyletic but unresolved group $(\mathrm{PP}=1.00, \mathrm{BS}=$ 97). Clade $M_{2}$ of $L$. ovalis forms a separate branch of the basal polytomy of the Microcarpium complex, whereas clade $\mathrm{M}_{1}$ of $L$. ovalis is a separate branch sister to clade $\mathrm{A}+$ clade $\mathrm{C} / \mathrm{I}$.

Among the eight clades of the Microcarpium complex, clades $\mathrm{M}_{1}$ and $\mathrm{M}_{2}$ contain only Ludwigia ovalis (section Miquelia), supporting the species as an allotetraploid. However, since clades $\mathrm{M}_{1}$ and $\mathrm{M}_{2}$ include no extant diploids, both diploid ancestors of $L$. ovalis had likely gone extinct.

Clade $\mathrm{A}$ is so named for the presence of the diploid Ludwigia palustris (AA). In addition to L. palustris, clade A also includes all tetraploids (XXXX) and the hexaploid L. alata (GGXXXX) of section Microcarpium, and the tetraploid L. arcuata (BBCC) and hexaploids $L$. brevipes (AABBCC) and L. repens (AABBCC) of section Isnardia (Fig. 5). Because our cpDNA tree (Fig. 4) has inferred L. arcuata (BBCC) as the maternal parent of both L. brevipes (AABBCC) and L. repens (AABBCC), the presence of these two hexaploids in clade A suggests that their paternal parent contributed genome A. Similarly, L. spathulata (AADD) received genome A through its paternal parent, given that it inherited through its maternal parent a genome closer to that of L. microcarpa (GG), as inferred from the cpDNA tree (Fig. 4). The presence of all tetraploids of section Microcarpium in clade A is consistent with the cpDNA tree (Fig. 4), while the presence of L. alata (GGXXXX) in this clade further resolves its genome formula from "GGXXXX" to "AAGGXX."

Clade $D / G$ is so named because of the presence of the diploid Ludwigia microcarpa (GG) and the tetraploid $L$. spathulata (AADD); as just noted, the other genome of L. spathulata has been identified in clade A of the PgiC tree (Fig. 5). The presence of both L. microcarpa (GG) and L. spathulata (AADD) in clade $\mathrm{D} / \mathrm{G}$ is also congruent with our inference (Fig. 4) that the maternal genome of L. spathulata and genome $\mathrm{G}$ are closely related. Clade D/G also includes the hexaploids ( $L$. alata [AAGGXX] and L. simpsonii [GGHHII]) and the octoploid L. curtissii (FFGGHHII) of section Microcarpium (Fig. 5), consistent with Peng's (1988) hypothesis (Fig. 2) and inference from our cpDNA tree (Fig. 4).

Although both Ludwigia linifolia (clade $\mathrm{F}_{1}$ ) and $L$. linearis (clade $\mathrm{F}_{2}$ ) were hypothesized to have the $\mathrm{F}$ genome, our $P g i C$ tree indicates that they do not form a single clade, and that L. linifolia (clade $\mathrm{F}_{1}$ ), not $L$. linearis (clade $\mathrm{F}_{2}$ ), contributed its $\mathrm{F}_{1}$ genome to the octoploid L. curtissii (FFGGHHII) as the paternal parent (Fig. 5); the cpDNA tree has identified L. simpsonii (GGHHII) as the maternal parent (Fig. 4).

Clade $\mathrm{B} / \mathrm{H}$ and clade $\mathrm{C} / \mathrm{I}$ do not include any diploid taxa but are so named because of the presence in both tetraploid Ludwigia arcuata (BBCC) and hexaploid $L$. simpsonii (GGHHII), given genome $\mathrm{G}$ of the latter has already been identified in clade $\mathrm{D} / \mathrm{G}$ (Fig. 5). Clade B/H includes all polyploid taxa of the Microcarpium complex except for L. spathulata (AADD), indicating the presence of the $\mathrm{B} / \mathrm{H}$ genome in all other polyploids (Fig. 5). Because our cpDNA tree has inferred that the tetraploids of section Microcarpium inherited genome A maternally (Fig. 4), the PgiC tree suggests that these tetraploids inherited their $\mathrm{B} / \mathrm{H}$ genome paternally (i.e., AABB). Consequently, the hexaploid L. alata (AAGGXX) can now be designated AABBGG (三 AABBDD). In both clades B/H and C/I, L. simpsonii-L. curtissii is sister to L. arcuata-L. brevipes - L. repens (Fig. 5), consistent with their morphological similarity (Peng, 1989) and our inference from the cpDNA tree that $L$. arcuata is likely the maternal parent of L. simpsonii (Fig. 4), indicating that genomes $\mathrm{B}$ and $\mathrm{C}$ are similar to $\mathrm{H}$ and I, respectively. By substituting $\mathrm{H}$ with $\mathrm{B}$ and I with $\mathrm{C}$, the genome complement of L. simpsonii and L. curtissii should be BBCCDD and BBCCDDFF, respectively.

Both accessions of Ludwigia sphaerocarpa (Anderson s.n. [81] and J. R. Abbott $23370[12+61]$, Table 1) possess four copies of $P g i C$ genes, two in clade A and two in clade B/H (Fig. 5, Supplementary Fig. S1). In both clades, the two copies of Anderson s.n. (81) are grouped either by themselves or with a copy of $J$. $R$. Abbott 23370, but the second copy of J. R. Abbott 23370 is grouped with L. lanceolata (Fig. 5, Supplementary Fig. S1). The presence of two copies of genome A and genome B/H is congruent with Peng's (1988) hypothesis that L. sphaerocarpa originated after hybridization between the interfertile tetraploids. The different genome components in J. R. Abbott 23370 and Anderson s.n. are also consistent with Peng's (1988) proposition that $L$. sphaerocarpa might have multiple origins. 

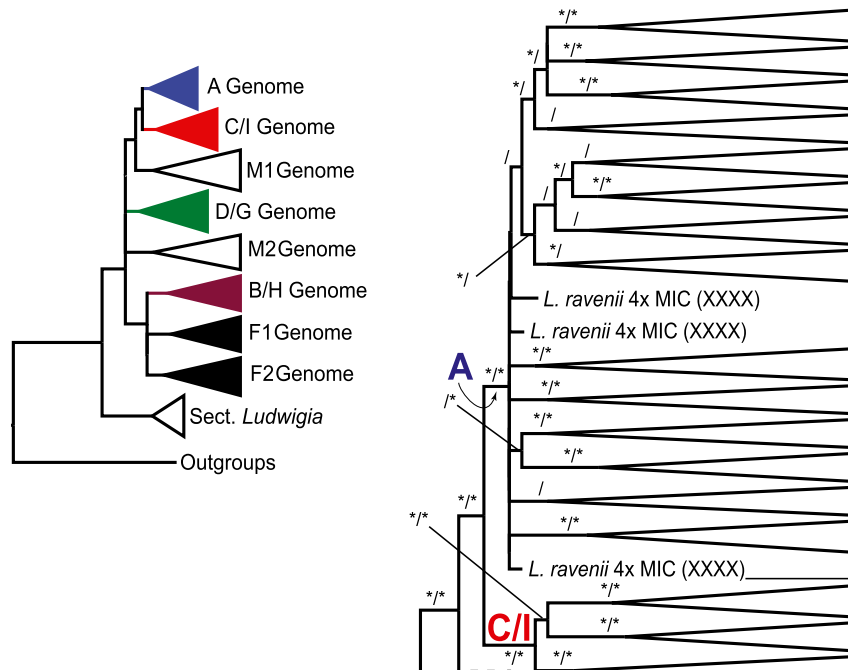

sphaerocarpa 4X $1261 \mathrm{MIC}$ (XXXX) lanceolata 4X MIC (XXXX) suffruticosa $4 \times$ MIC (XXXX) alata 6x MIC (GGXXXX) sphaerocarpa $4 \mathrm{X}$ 12,61,81 MIC (XXXX) L. repens $6 \mathrm{x}$ ISN (AABBCC) brevipes $6 x$ ISN (AABBCC) repens $6 \mathrm{x}$ ISN (AABBCC) repens $6 \times$ ISN (AABBCC) palustris $2 \times$ ISN (AA)

spathulata $4 \times$ ISN (AADD) L. pilosa 4X MIC (XXXX)

glandulosa ssp. brachycarpa 4x MIC (XXXX) glandulosa ssp. glandulosa $4 \mathrm{x}$ MIC (XXXX) sphaerocarpa $4 \times 81$ MIC (XXXX) . polycarpa 4X MIC (AAXX)

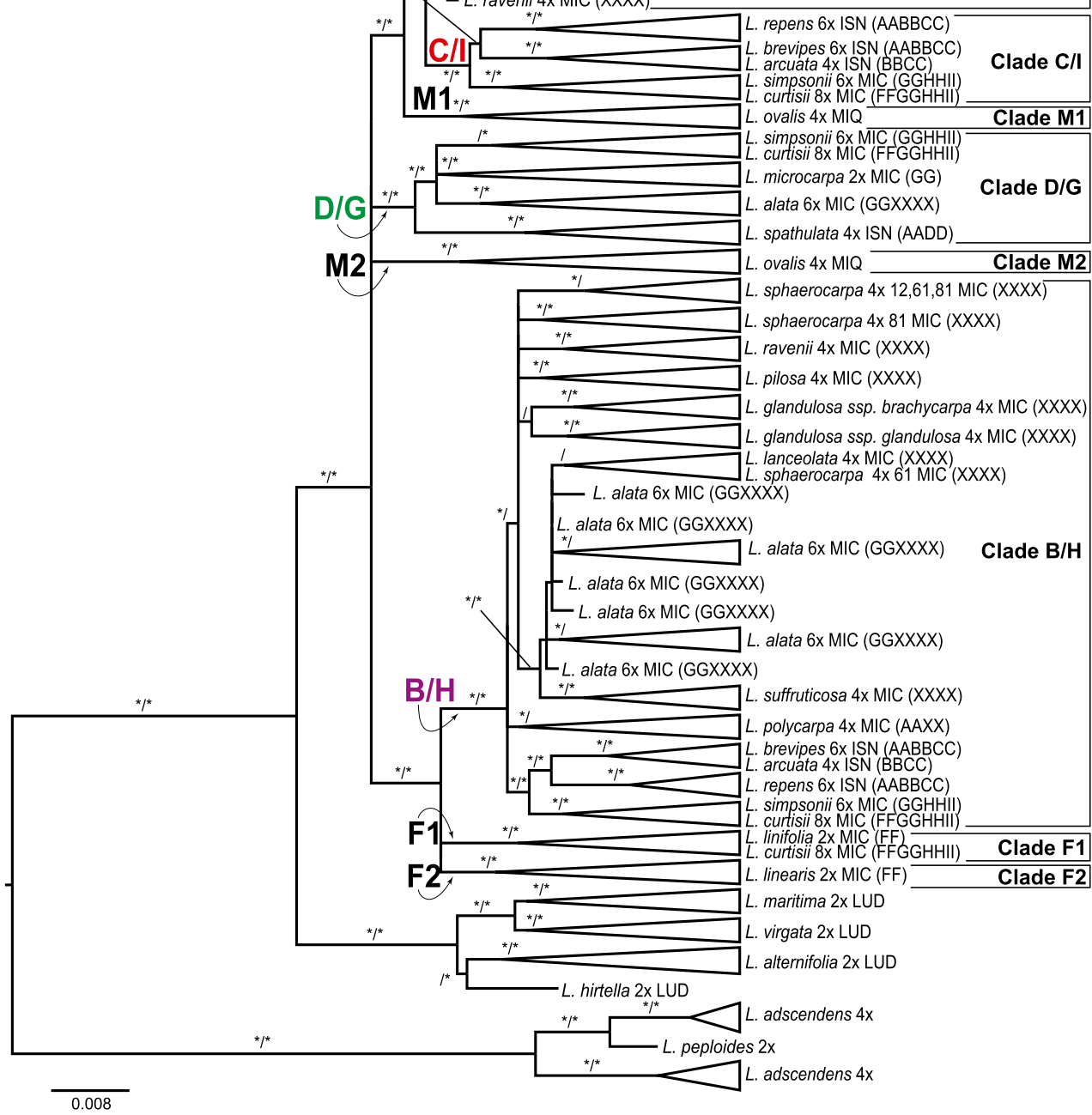

Figure 5. The collapsed PgiC maximum likelihood tree of the North Temperate haplostemonous Ludwigia L. clade. Uncollapsed tree is depicted in Supplementary Figure S1. Asterisks on the branches show Bayesian posterior probabilities $>0.9 /$ bootstrap percentages $>70$. Ploidy level, section code (see Table 1), and genome hypothesized in earlier studies (see Fig. 2) are provided for each terminal node. Sample numbers are included after ploidy levels only for L. sphaerocarpa Elliott (see Table 1). Letters in bold refer to genome designation. The scale bar indicates the branch length. 
Since all seven tetraploids in section Microcarpium have both genomes A and B/H (Fig. 5), an additional phylogeny containing only these tetraploids was reconstructed by concatenating genome $\mathrm{A}$ and $\mathrm{B} / \mathrm{H}$ sequences to understand their evolutionary relationships. This additional tree is shown in Supplementary Figure S2 (see also Supplementary Appendix S3).

\section{BIOGEOGRAPHIC INFERENCE}

The representative ML and BI trees were reconstructed based on 52 selected $P$ giC clones representing all genomes $\left(\mathrm{A}, \mathrm{B} / \mathrm{H}, \mathrm{C} / \mathrm{I}, \mathrm{D} / \mathrm{G}, \mathrm{F}_{1}, \mathrm{~F}_{2}, \mathrm{M}_{1}\right.$, and $\left.\mathrm{M}_{2}\right)$ of all studied Ludwigia taxa and three clones from outgroups (two from L. adscendens and one from L. peploides). Only the representative ML tree is shown here (Fig. 6, Supplementary Appendix S4). The results of both parsimony and likelihood approaches of ancestral area reconstruction using Mesquite are consistent. However, because the likelihood approach is not capable of tracking polymorphic states, some nodes are left uncertain. Consequently, results of parsimony analyses are shown in the ML tree (Fig. 6). Analysis using Mesquite identifies North America as the ancestral area for the NTH Ludwigia, suggesting a dispersal event for the disjunct East Asian L. ovalis.

\section{Discussion}

\section{PHYLOGENETIC RELATIONSHIP OF SECTION LUDWIGIA}

Both the diploid section Ludwigia and the multiploid Microcarpium complex are well-supported monophyletic groups in both the cpDNA tree and $P$ giC tree (Figs. 4, 5), in accord with previous hypotheses (Raven \& Tai, 1979; Wagner et al., 2007; Liu et al., 2017). Within section Ludwigia, the PgiC tree indicates that the clade of L. alternifolia L. - L. hirtella Raf. is sister to the clade of $L$. maritima R. M. Harper-L. virgata Michx., as predicted based on prior morphological and phylogenetic studies (Harper, 1904; Munz, 1965; Liu et al., 2017). This relationship is also consistent with the cpDNA tree (Fig. 4) except for one sample (J. R. Abbott 23333 [16], Table 1) of L. maritima placed as the basal branch of section Ludwigia. More comprehensive sampling of L. maritima and L. virgata using additional DNA regions will be needed to clarify the delimitations and relationships of the two species.

\section{RETICULATE EVOLUTION OF THE MICROCARPIUM COMPLEX}

Within the Microcarpium complex, both cpDNA and PgiC trees (Figs. 4, 5) correspond well to Peng's (1988, 1989) and Peng et al.'s (2005) hypotheses of the relationships in sections Isnardia and Microcarpium (Fig. 2). Integrating Peng's cytological results with our trees, we propose a new model for the reticulate evolution in NTH Ludwigia (Fig. 7).

The PgiC tree indicates that the East Asian species Ludwigia ovalis (monospecific section Miquelia) is an allotetraploid consisting of genomes $\mathrm{M}_{1}$ and $\mathrm{M}_{2}$, concordant with results from Liu et al. (2017). In the PgiC tree (Fig. 5), genome $\mathrm{M}_{2}$ appears as part of the basal polytomy of the Microcarpium complex, whereas genome $\mathrm{M}_{1}$ is sister to the $\mathrm{A}-\mathrm{C} / \mathrm{I}$ clade. This relationship suggests that $M_{2}$ might be the maternal genome and $M_{1}$ the paternal genome of L. ovalis (Fig. 7), given L. ovalis is placed basal to the rest of the Microcarpium complex in the cpDNA tree (Fig. 4).

Both the cpDNA and PgiC trees indicate that neither section Isnardia nor section Microcarpium as currently delimited is a monophyletic group (Figs. 4, 5), congruent with the results of Liu et al. (2017). These results also support Peng's (1988) hypothesis (Fig. 2A) and further suggest that six of the seven tetraploid species in section Microcarpium (Ludwigia glandulosa, L. lanceolata, L. pilosa, L. polycarpa, L. ravenii, and L. suffruticosa) are the progeny of a common allotetraploid ancestor (AABB), which inherited maternal $\mathrm{A}$ and paternal B/H genomes (Fig. 6). However, our PgiC tree indicates that L. sphaerocarpa possesses four homeo$\operatorname{logs}$, two of clade A and two of clade B/H, respectively (Fig. 5, Supplementary Fig. S2). Based on the orientation of seed surface cells, Peng (1989) hypothesized that L. sphaerocarpa had a hybrid origin, likely resulting from hybridization between interfertile tetraploid species of section Microcarpium. Given its likely hybrid origin, the presence of four homeologs of $P g i C$ in both accessions suggests that $L$. sphaerocarpa could be a homoploid hybrid species between two allotetraploid species of section Microcarpium (Ferguson \& Sang, 2001). However, the two accessions of L. sphaerocarpa have different genome compliments (Fig. 5, Supplementary Fig. S2), suggesting that the species might have arisen from at least two hybridization events, one likely involving L. lanceolata (Levin, 2002; Barker et al., 2016).

Congruent with Peng's (1988) proposition, our PgiC tree suggests that hexaploid Ludwigia alata was likely derived following hybridization between a diploid $L$. microcarpa (section Microcarpium; D/G genome; 9 ) and tetraploid species (AABB; $\left.\sigma^{*}\right)$ closely related to $L$. lanceolata, L. sphaerocarpa, and L. suffruticosa. Our data also suggest that the other hexaploid of section Microcarpium, L. simpsonii, is an allohexaploid derived from hybridization between diploid L. microcarpa (ठ) and an unidentified/extinct tetraploid ancestor (BBCC; P) closely related to $L$. arcuata of section Isnardia, supporting Peng's (1988) hypotheses based on cytology and morphology (Fig. 2A). The octoploid L. curtissii of section Microcarpium appears to be derived from 

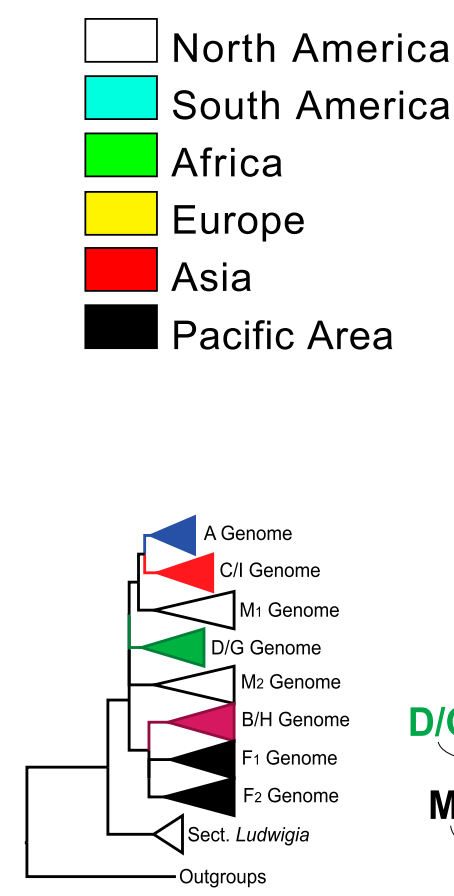

L. ravenii $50 \mathrm{~g} \bigcirc$
L. spathulata $28 \mathrm{~g} \bigcirc$

L. sphaerocarpa $61 \mathrm{LO}$

L. alata $47 \mathrm{~b} \bigcirc$

L. suffruticosa $29 a \bigcirc$

L. L. sphaerocarpa $81 \mathrm{e} \bigcirc$

0.86 - L. repens $230 \bigcirc$

L. palustris $\varnothing$

L. polycarpa $62 \mathrm{~d} \bigcirc$

1.91- 2 L. sphaerocarpa $81 \mathrm{j} O$

L. glandulosa ssp. brachycarpa $57 \mathrm{~d}$. glandulosa

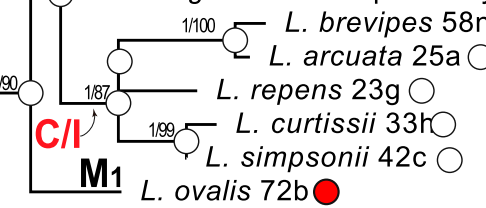

M. ovalis $72 \mathrm{~b}$

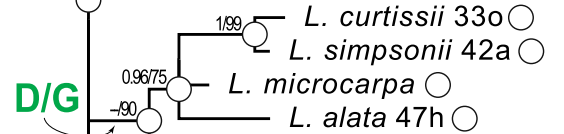

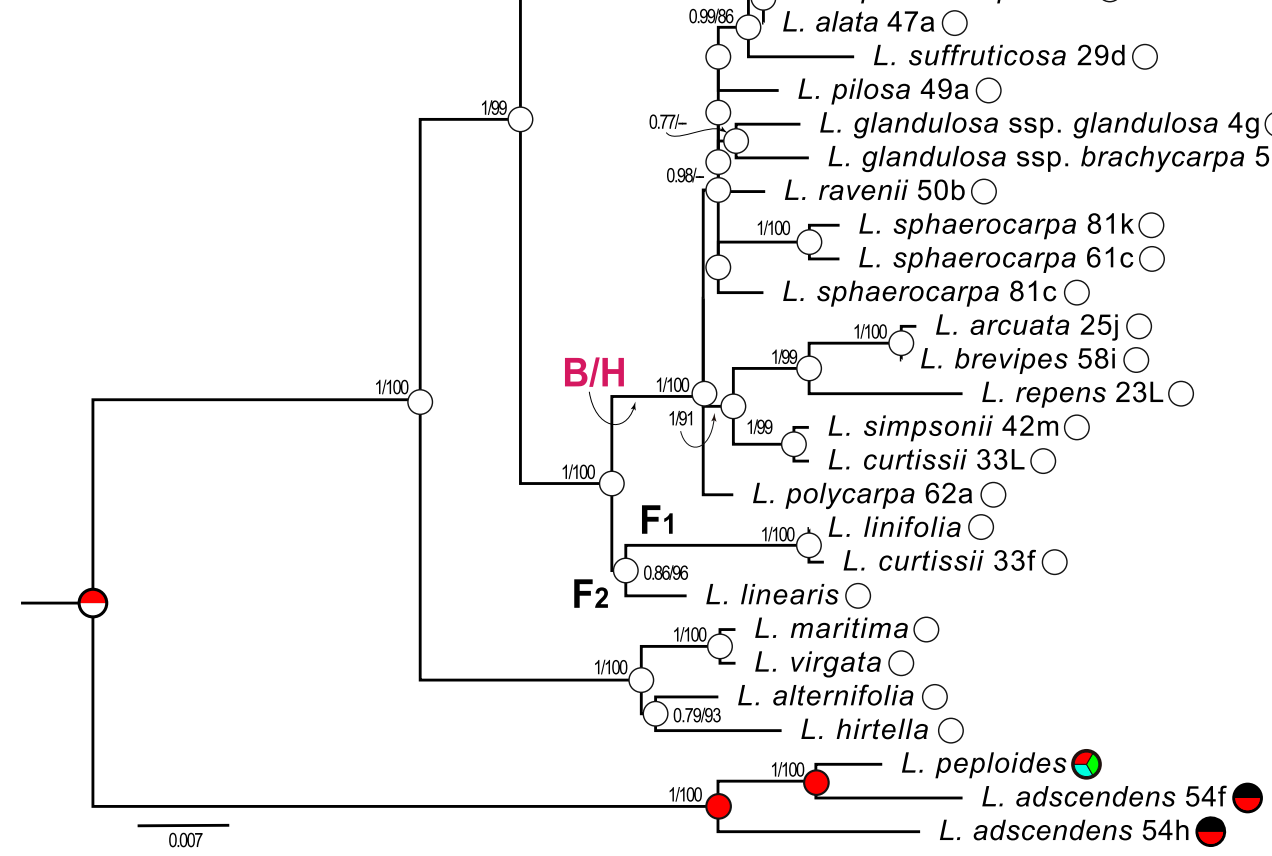

Figure 6. Ancestral area reconstruction using Mesquite. The scale bar indicates the branch length. 


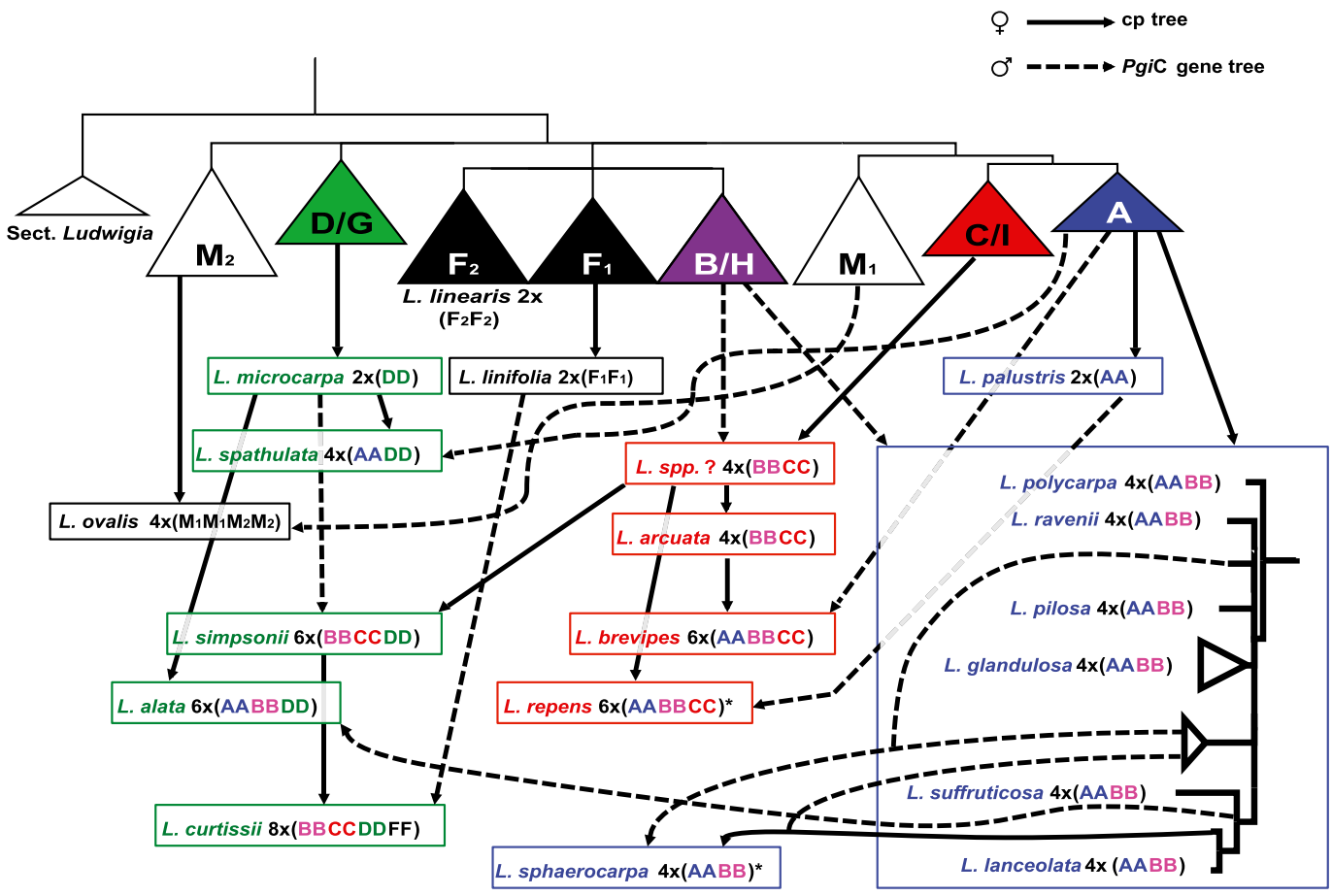

Figure 7. Reconstruction of the polyploid and reticulate evolution of the North Temperate haplostemonous Ludwigia L. clade based on the PgiC and chloroplast trees (Figs. 4, 5) and cytological and hybridization analyses of Peng (1988, 1989) and Peng et al. (2005). Backbone of tree is collapsed PgiC tree extracted from Figure 5, with genomes indicated in bold. Inset at right is extracted from Supplementary Figure S2, the PgiC tree based on genomes A and B for all tetraploid species in section Microcarpium Munz. Ploidy level and genome designation is included for each species. Asterisks indicate species with multiple origins (see text for details). Solid arrows connect species with maternal donors/genomes, and dashed arrows with paternal donors/genomes.

hybrids between L. simpsonii $(6 \times$; 9$)$ and L. linifolia $\left(2 \times\right.$; genome $\left.\mathrm{F} ; \delta^{-}\right)$.

Our analyses also infer that the two tetraploids of section Isnardia-Ludwigia spathulata and L. arcua$t a$-are derived from different genomes (Fig. 7), as proposed by Peng et al. (2005). Ludwigia spathulata derived from hybrids between L. microcarpa $(2 \times$; genome $\mathrm{D} / \mathrm{G}$; \%) and an unidentified/extinct diploid ancestor with genome A ( $\left.\boldsymbol{\delta}^{*}\right)$. Ludwigia arcuata derived from an unidentified/extinct tetraploid ancestor (BBCC) that also may have contributed to the origin of $L$. simpsonii (section Microcarpium) and L. repens (section Isnardia). The living diploid relatives of the genomes A, $\mathrm{B} / \mathrm{H}$, and $\mathrm{C} / \mathrm{I}$ that contributed to these two tetraploids are either unidentified or extinct. In view of earlier intensive collecting and systematic studies on the NTH Ludwigia clade (Peng \& Tobe, 1987; Peng, 1988, 1989; Tobe et al., 1988; Peng et al., 2005), it is more likely that the missing diploid progenitors had gone extinct rather than unidentified. In partial agreement with Peng et al. (2005) (Fig. 2B), our phylogenies suggest that the two hexaploid species of section Isnardia (L. brevipes and $L$. repens) evolved independently — but not from reciprocal directions (Peng et al., 2005)—though both of them inherited genomes $\mathrm{A}, \mathrm{B} / \mathrm{H}$, and $\mathrm{C} / \mathrm{I}$. Ludwigia brevipes is likely a hybrid between the tetraploid $L$. arcuata (BBCC, P) and an extinct diploid ancestor with genome A ( $\left.{ }^{\star}\right)$. Our analyses suggest that $L$. repens may have evolved multiple times, with the maternal donor probably the tetraploid ancestor (BBCC) that also gave rise to $L$. arcuata and $L$. simpsonii, and the paternal donor being either L. palustris (AA) or an extinct diploid closely related to $L$. palustris.

Even though our species-level phylogenies do not detect multiple origins for most polyploids in the NTH Ludwigia clade except for $L$. sphaerocarpa and $L$. repens (Fig. 7), it cannot be ruled out that other polyploids in the clade might also have multiple origins (Levin, 2002; Barker et al., 2016). Further analyses with additional samples of each polyploid species would be needed to test for other possible multiple origins.

While our analyses have thoroughly unraveled the reticulate evolution of the Microcarpium complex as discussed above, the relatively small amount of sequence data (only four chloroplast and one nuclear single-copy region), even though they provide a wellsupported phylogeny, might not yet present a complete understanding of the evolutionary complexity of this 
group. Additional single-copy nuclear genes and/or genome-wide data will be needed in further phylogenetic studies to test our evolutionary inference (e.g., Hipp et al., 2019; Valcárcel \& Wen, 2019; White et al., 2019).

\section{FURTHER IMPLICATIONS OF POLYPLOID AND RETICULATE} EVOLUTION

Within the extensively polyploid Microcarpium complex, only five of the 20 extant species are diploids. Our analyses suggest that four or as many as eight diploid progenitors in the complex went extinct after they gave rise to the extant polyploids (Fig. 7). Although these diploid progenitors are extinct, their genomes are preserved in the extant polyploids, as detected by cytological work (Peng, 1988; Peng et al., 2005) and our molecular analysis (Fig. 7). Using molecular techniques, an increasing number of extinct diploid progenitors of extant polyploid plants have been detected in various groups, e.g., one or more extinct diploids in Glycine L. subg. Glycine (Doyle et al., 2004), two extinct diploids closely related to Hordeum murinum (Jakob \& Blattner, 2010), and at least two extinct diploids in Ludwigia sect. Macrocarpon (Liu et al., 2018). The extinction of the diploid progenitors in the Microcarpium complex might be associated with climate cooling in the Tertiary, which drove extinctions in many other north-temperate plant lineages (Tiffney, 1985; Tiffney \& Manchester, 2001; Wen et al., 2016). Moreover, many studies focusing on polyploids and their existing diploid progenitors have shown that polyploids often are more ecologically successful than related diploids, occupying larger geographical and ecological ranges (Levin, 1975; Lowry \& Lester, 2006; te Beest et al., 2012). The ecologically more robust polyploid descendants may have outcompeted their diploid progenitors in the NTH Ludwigia clade, resulting in the extinction of many of the diploids in the lineage.

\section{BIOGEOGRAPHIC INFERENCES}

Analysis of geographic distribution (Fig. 6) supports earlier propositions that the evolution of the NTH Ludwigia clade centered in North America (Raven, 1963; Eyde, 1981; Tobe et al., 1988). The only exception is $L$. ovalis, which is endemic to East Asia, and $L$. palustris, which is widely distributed in North America, central and northern South America, Eurasia, and Africa (Raven, 1963; Peng et al., 2005; Wagner et al., 2007). Raven (1963) and Peng et al. (2005) proposed that $L$. ovalis and L. palustris may be relicts of the Arcto-Tertiary Geoflora. The report of Miocene fossil Ludwigia seeds from Denmark (Friis, 1985) that could be assigned to section Isnardia (Tobe et al., 1988) supports this proposition. Our PgiC tree indicates that the tetraploid L. ovalis is composed of genomes $\mathrm{M}_{1}$ and $\mathrm{M}_{2}$ (Figs. 5, 7), which are embedded within clades of the Microcarpium complex distributed in North America. Given this, L. ovalis must have originated in North America, dispersed to East Asia, possibly through the Bering land bridge (e.g., Li et al., 2015; Patiño et al., 2016; Wen et al., 2016), and subsequently become extinct in North America.

\section{TAXONOMIC REVISION}

Our analyses indicate that neither section Isnardia nor Microcarpium is monophyletic as currently circumscribed, and Ludwigia ovalis (monospecific section Miquelia) is an allotetraploid derived from two earlybranching genomes in the Microcarpium complex (Figs. 4-6). By applying the principle of monophyly and using the earliest available name, we propose to combine the three sections into an expanded section Isnardia (L.) W. L. Wagner \& Hoch (Wagner et al., 2007).

\section{Taxonomic Treatment}

Ludwigia L. sect. Isnardia (L.) W. L. Wagner \& Hoch, Syst. Bot. Monogr. 83: 36. 2007. Isnardia L., Sp. Pl. 1: 120. 1753. TYPE: Isnardia palustris L. [三 Ludwigia palustris (L.) Elliott].

Ludwigia sect. Microcarpium Munz, Bull. Torrey Bot. Club 71: 154. 1944, syn. nov. TYPE: Ludwigia pilosa Walter.

Ludwigia sect. Miquelia P. H. Raven, Reinwardtia 6: 337. 1963, syn. nov. TYPE: Ludwigia ovalis Miq.

Included species. Ludwigia alata Elliott, L. arcuata Walter, L. brevipes (Long) Eames, L. curtissii Chapm., L. glandulosa Walter subsp. glandulosa, L. glandulosa subsp. brachycarpa C.-I Peng, L. lanceolata Elliott, L. linearis Walter, L. linifolia Poir., L. microcarpa Michx., L. ovalis Miq., L. palustris (L.) Elliott, L. pilosa Walter, L. polycarpa Short \& R. Peter, L. ravenii C.-I Peng, L. repens J. R. Forst., L. simpsonii Chapm., L. spathulata Torrey \& A. Gray, L. sphaerocarpa Elliott, L. stricta (C. Wright ex Griseb.) C. Wright, L. suffruticosa Walter.

\section{ConcLusions}

Using both the biparental nuclear single-copy $P g i C$ region and four maternally inherited chloroplast regions (rpL16, rpoB-trnC, trnL-trnF, and ycf6-psbM), we reconstructed the phylogeny of the NTH Ludwigia group. These phylogenies indicate that the NTH Ludwigia clade is monophyletic, and that the diploid section Ludwigia and a redefined multiploid section Isnardia (Microcarpium complex, composed of former sections Isnardia, Microcarpium, and Miquelia) are 
well-supported sister clades. Within the redefined section Isnardia, our results largely support hypotheses proposed in Peng (1988) and part of Peng et al. (2005) (Fig. 2). Eight genomes are recognized in the complex, and the reticulate evolution of each taxon in the section has been reconstructed (Fig. 7). Four, or possibly eight, extinct diploid progenitors that contributed to extant polyploids are also inferred in our phylogenies. The Tertiary climate change and the ecological success of the polyploids may have contributed to the extinction of the diploid progenitors.

\section{Literature Cited}

Alvarez, I. \& J. F. Wendel. 2003. Ribosomal ITS sequences and plant phylogenetic inference. Molec. Phylogen. Evol. 29: 417-434. https://doi.org/10.1016/S1055-7903(03) 00208-2

Arnold, M. L. 1997. Natural Hybridization and Evolution. Oxford University Press, New York.

Baldwin, B. G., M. J. Sanderson, J. M. Porter, M. F. Wojciechowski, C. S. Campbell \& M. J. Donoghue. 1995. The ITS region of nuclear ribosomal DNA: A valuable source of evidence on angiosperm phylogeny. Ann. Missouri Bot. Gard. 82: 247-277.

Barker, M. S., B. C. Husband \& J. C. Pires. 2016. Spreading Winge and flying high: The evolutionary importance of polyploidy after a century of study. Amer. J. Bot. 103: 1139-1145. https://doi.org/10.3732/ajb.1600272

Chung, K.-F., W.-C. Leong, R. R. R. Rubite, R. Repin, R. Kiew, Y. Liu \& C.-I Peng. 2014. Phylogenetic analyses of Begonia sect. Coelocentrum and allied limestone species of China shed light on the evolution of Sino-Vietnamese karst flora. Bot. Stud. 55: 1-15.

Darriba, D., G. L. Taboada, R. Doallo \& D. Posada. 2012. jModelTest 2: More models; new heuristics and parallel computing. Nat. Methods 9: 772. https://doi.org/10.1038/ nmeth.2109

Doyle, J. J., J. L. Doyle, J. T. Rauscher \& A. H. D. Brown. 2004. Diploid and polyploid reticulate evolution throughout the history of the perennial soybeans (Glycine subgenus Glycine). New Phytol. 161: 121-132. https://doi.org/10.1046/ j.1469-8137.2003.00949.x

Eyde, R. H. 1977. Reproductive structures and evolution in Ludwigia (Onagraceae). I. Androecium, placentation, merism. Ann. Missouri Bot. Gard. 64: 644-655.

Eyde, R. H. 1978. Reproductive structures and evolution in Ludwigia (Onagraceae). II. Fruit and seed. Ann. Missouri Bot. Gard. 65: 656-675.

Eyde, R. H. 1981. Reproductive structures and evolution in Ludwigia (Onagraceae). III. Vasculature, nectaries, conclusions. Ann. Missouri Bot. Gard. 68: 379-412.

Ferguson, D. \& T. Sang. 2001. Speciation through homoploid hybridization between allotetraploids in peonies (Paeonia). Proc. Natl. Acad. Sci. U.S.A. 98: 3915-3919.

Ford, V. S. \& L. D. Gottlieb. 1999. Molecular characterization of $\mathrm{PgiC}$ in a tetraploid plant and its diploid relatives. Evolution 53: 1060-1067.

Ford, V. S. \& L. D. Gottlieb. 2002. Single mutations silence PgiC2 genes in two very recent allotetraploid species of Clarkia. Evolution 56: 699-707.

Ford, V. S. \& L. D. Gottlieb. 2007. Tribal relationships within Onagraceae inferred from PgiC sequences. Syst. Bot. 32: 348-356. https://doi.org/10.1600/036364407781179725
Ford, V. S., J. Lee, B. G. Baldwin \& L. D. Gottlieb. 2006. Species divergence and relationships in Stephanomeria (Compositae): PgiC phylogeny compared to prior biosystematic studies. Amer. J. Bot. 93: 480-490. https://doi.org/ 10.3732/ajb.93.3.480

Friis, E. M. 1985. Angiosperm fruits and seeds from the Middle Miocene of Jutland (Denmark). Kobenhavn, Denmark. Det Kongelige Danske Videnskaberne Selskab. Biologiske Skrifter, Kobenhavn.

Gong, X., K.-H. Hung, Y.-W. Ting, T.-W. Hsu, L. Malikova, H. T. Tran, C.-L. Huang, et al. 2017. Frequent gene flow blurred taxonomic boundaries of sections in Lilium L. (Liliaceae). PLoS One 12: E0183209. https://doi.org/10.1371/ journal.pone.0183209.

Gottlieb, L. D. \& V. S. Ford. 1996. Phylogenetic relationships among the sections of Clarkia (Onagraceae) inferred from the nucleotide sequences of PigC. Syst. Bot. 21: 45-62.

Govindarajulu, R., M. Parks, J. A. Tennessen, A. Liston \& T. L. Ashman. 2015. Comparison of nuclear, plastid, and mitochondrial phylogenies and the origin of wild octoploid strawberry species. Amer. J. Bot. 102: 544-554. https:// doi.org/10.3732/ajb.1500026

Harper, R. M. 1904. Two hitherto confused species of Ludwigia. Torreya 4: 161-164.

Hipp, A. L., A. T. Whittemore, M. Garner, M. Hahn, E. Fitzek, E. Guichoux, J. Cavender-Bares, et al. 2019. Genomic identity of white oak species in an eastern North American syngameon. Ann. Missouri Bot. Gard. 104(3): 455-477. https://doi.org/10.3417/2019434

Hsu, T.-W. 2010. Phylogenetics of the Genus Ludwigia Section Microcarpium (Onagraceae) (in Chinese). Ph.D. Dissertation, Department of Life Sciences, National Cheng Kung University, Tainan, Taiwan.

Huelsenbeck, J. P. \& F. Ronquist. 2001. MrBayes: Bayesian inference of phylogeny. Bioinformatics 17: 754-755. https:// doi.org/10.1093/bioinformatics/17.8.754

Hung, K.-H., B. A. Schaal, T.-W. Hsu, Y.-C. Chiang, C.-I Peng \& T.-Y. Chiang. 2009. Phylogenetic relationships of diploid and polyploid species in Ludwigia sect. Isnardia (Onagraceae) based on chloroplast and nuclear DNAs. Taxon 58: 1216-1225.

Jakob, S. S. \& F. R. Blattner. 2010. Two extinct diploid progenitors were involved in allopolyploid formation in the Hordeum murinum (Poaceae: Triticeae) taxon complex. Molec. Phylogen. Evol. 55: 650-659. https://doi.org/10.1016/ j.ympev.2009.10.021

Jiao, Y. \& A. H. Paterson. 2014. Polyploidy-associated genome modifications during land plant evolution. Philos. Trans., Ser. B 369: 20130355. https://doi.org/10.1098/ rstb.2013.0355

Juslén, A., H. Väre \& N. Wikström. 2011. Relationships and evolutionary origins of polyploid Dryopteris (Dryopteridaceae) from Europe inferred using nuclear pgiC and plastid trnL-F sequence data. Taxon 60: 1284-1294.

Katoh, K. \& D. M. Standley. 2013. MAFFT multiple sequence alignment software version 7: Improvements in performance and isability. Molec. Biol. Evol. 30: 772-780. https://doi.org/ 10.1093/molbev/mst010

Katoh, K., K. Misawa, K. Kuma \& T. Miyata. 2002. MAFFT: A novel method for rapid multiple sequence alignment based on fast Fourier transform. Nucleic Acids Res. 30: 3059-3066. https://doi.org/10.1093/nar/gkf436

Kono, Y., K.-F. Chung, C.-H. Chen, Y. Hoshi, H. Setoguchi, C.-H. Chou, K. Oginuma, et al. 2012. Intraspecific karyotypic polymorphism is highly concordant with allozyme variation in Lysimachia mauritiana (Primulaceae: Myrsinoideae) in Taiwan: Implications for the colonization history 
and dispersal patterns of coastal plants. Ann. Bot. 110: 1119-1135. https://doi.org/10.1093/aob/mcs192

Levin, D. A. 1975. Minority cytotype exclusion in local plant populations. Taxon 24: 35. https://doi.org/10.2307/1218997

Levin, D. A. 2002. The Role of Chromosomal Change in Plant Evolution. Oxford University Press, New York.

Li, J.-T., J.-S. Wang, H.-H. Nian, S. N. Litvinchuk, J. Wang, Y. Li, D.-Q. Rao, et al. 2015. Amphibians crossing the Bering Land Bridge: Evidence from holarctic treefrogs (Hyla, Hylidae, Anura). Molec. Phylogen. Evol. 87: 80-90. https:// doi.org/10.1016/j.ympev.2015.02.018

Lipman, M. J., M. Chester, P. S. Soltis \& D. E. Soltis. 2013. Natural hybrids between Tragopogon mirus and T. miscellus (Asteraceae): A new perspective on karyotypic changes following hybridization at the polyploid level. Amer. J. Bot. 100: 2016-2022. https://doi.org/10.3732/ajb.1300036

Liu, S.-H., P. C. Hoch, M. Diazgranados, P. H. Raven \& J. C. Barber. 2017. Multi-locus phylogeny of Ludwigia (Onagraceae): Insights on infrageneric relationships and the current classification of the genus. Taxon 66: 1112-1127. https:// doi.org/10.12705/665.7

Liu, S.-H., C. E. Edwards, P. C. Hoch, P. H. Raven \& J. C. Barber. 2018. Genome skimming provides new insight into the relationships in Ludwigia section Macrocarpon, a polyploid complex. Amer. J. Bot. 105: 875-887. https://doi.org/ 10.1002/ajb2.1086

Lowry, E. \& S. E. Lester. 2006. The biogeography of plant reproduction: Potential determinants of species' range sizes. J. Biogeogr. 33: 1975-1982. https://doi.org/10.1111/j.13652699.2006.01562.x

Maddison, W. P. \& D. R. Maddison. 2018. Mesquite: A modular system for evolutionary analysis. Version 3.40. <http://mesquiteproject.org >, accessed 29 April 2020 .

Mandák, B., K. Krak, P. Vít, M. N. Lomonosova, A. Belyayev, F. Habibi, L. Wang, et al. 2018. Hybridization and polyploidization within the Chenopodium album aggregate analysed by means of cytological and molecular markers. Molec. Phylogen. Evol. 129: 189-201. https://doi.org/10.1016/ j.ympev.2018.08.016

Miller, M. A., W. Pfeiffer \& T. Schwartz. 2010. Creating the CIPRES Science Gateway for inference of large phylogenetic trees. In Proceedings of the Gateway Computing Environments Workshop (GCE). Gateway Computing Environments Workshop (GCE), New Orleans.

Munz, P. A. 1942. Studies in Onagraceae XII: A revision of the new world species of Jussiaea. Darwiniana 4: 179-284.

Munz, P. A. 1965. Onagraceae. North American Flora, Ser. 2, Part 5, 2.

Patiño, J., B. Goffinet, M. Sim-Sim \& A. Vanderpoorten. 2016. Is the sword moss (Bryoxiphium) a preglacial Tertiary relict? Molec. Phylogen. Evol. 96: 200-206. https://doi.org/10.1016/ j.ympev.2015.12.004.

Peng, C.-I. 1983. Triploidy in Ludwigia in Taiwan, and the discovery of Ludwigia adscendens (Onagraceae). Bot. Bull. Acad. Sin. 24: 129-134.

Peng, C.-I. 1988. The biosystematics of Ludwigia sect. Microcarpium (Onagraceae). Ann. Missouri Bot. Gard. 75: 970-1009.

Peng, C.-I. 1989. The systematics and evolution of Ludwigia sect. Microcarpium (Onagraceae). Ann. Missouri Bot. Gard. 76: 221-302.

Peng, C.-I. 1990. Ludwigia $\times$ taiwanensis (Onagraceae), a new species from Taiwan, and its origin. Bot. Bull. Acad. Sin. 31: 343-349.

Peng, C.-I \& H. Tobe. 1987. Capsule wall anatomy in relation to capsular dehiscence in Ludwigia sect. Microcarpium (Onagraceae). Amer. J. Bot. 74: 1102-1110.
Peng, C.-I, C. L. Schmidt, P. C. Hoch \& P. H. Raven. 2005. Systematics and evolution of Ludwigia section Dantia (Onagraceae). Ann. Missouri Bot. Gard. 92: 307-359.

Peng, C.-I, H. Wang, Y. Kono \& H.-A. Yang. 2014. Begonia wui-senioris (sect. Platycentrum, Begoniaceae), a new species from Myanmar. Bot. Stud. 55: 13. https://doi.org/ 10.1186/1999-3110-55-13

Pesamosca, S. C. \& I. I. Boldrini. 2015. Ludwigia litoranea (Onagraceae), a new species from coastal southern Brazil. Phytotaxa 230: 183. http://dx.doi.org/10.3897/zookeys.150.2109

Praglowski, J., J. J. Skvarla, P. H. Raven \& J. W. Nowicke. 1983. Onagraceae Juss.: Fuchsieae L./Jussiaeeae L. World Pollen Spore Fl. 12: 1-41.

Ramamoorthy, T. P. \& E. M. Zardini. 1987. The systematics and evolution of Ludwigia sect. Myrtocarpus sensu lato (Onagraceae). Monogr. Syst. Bot. Missouri Bot. Gard. 19: 1-120.

Rambaut, A. 2014. FigTree v1.4.2. < http://tree.bio.ed.ac.uk/ software/figtree/>, accessed 29 April 2020.

Raven, P. H. 1963. The Old World species of Ludwigia (including Jussiaea), with a synopsis for the genus (Onagraceae). Reinwardtia 6: 327-427.

Raven, P. H. 1979. A survey of reproductive biology in Onagraceae. New Zealand J. Bot. 17: 575-593. https:// doi.org/10.1080/0028825X.1979.10432572

Raven, P. H. \& W. Tai. 1979. Observations of chromosomes in Ludwigia (Onagraceae). Ann. Missouri Bot. Gard. 66: 862-879. https://doi.org/10.2307/2398926

Rieseberg, L. H. \& J. H. Willis. 2007. Plant speciation. Science 317: 910-914. https://doi.org/10.1126/science.1137729

Ronquist, F., M. Teslenko, P. van der Mark, D. L. Ayres, A. Darling, S. Hohna, B. Larget, et al. 2012. MrBayes 3.2: Efficient Bayesian phylogenetic inference and model choice across a large model space. Syst. Biol. 61: 539-542. https:// doi.org/10.1093/sysbio/sys029

Schmidt, C. L. 1967. A Biosystematic Study of Ludwigia Sect. Dantia (Onagraceae). Ph.D. Dissertation, Stanford University, Stanford.

Shaw, J., E. B. Lickey, J. T. Beck, S. B. Farmer, W. Liu, J. Miller, K. C. Siripun, et al. 2005. The tortoise and the hare II: Relative utility of 21 noncoding chloroplast DNA sequences for phylogenetic analysis. Amer. J. Bot. 92: 142-166. https:// doi.org/10.3732/ajb.92.1.142

Sikes, D. S. \& P. O. Lewis. 2001. Beta software, version 1. PAUPRat: PAUP* implementation of the parsimony ratchet. Distributed by the authors. Department of Ecology and Evolutionary Biology, University of Connecticut, Storrs. <http:// www.iab.uaf.edu/people/derek_sikes/software2.htm $>$, accessed 29 April 2020.

Small, R. L., R. C. Cronn \& J. E. Wendel. 2004. Use of nuclear genes for phylogeny reconstruction in plants. Aust. Syst. Bot. 17: 145-170. https://doi.org/10.1071/SB03015

Soltis, D. E. \& P. S. Soltis. 1998. Choosing an approach and an appropriate gene for phylogenetic analysis. Pp. 1-42 in D. E. Soltis, P. S. Soltis \& J. J. Doyle (editors), Molecular Systematics of Plants II. Springer, New York.

Soltis, D. E., C. J. Visger \& P. S. Soltis. 2014. The polyploidy revolution then.... and now: Stebbins revisited. Amer. J. Bot. 101: 1057-1078. https://doi.org/10.3732/ajb.1400178

Stamatakis, A. 2014. RAxML version 8: A tool for phylogenetic analysis and post-analysis of large phylogenies. Bioinformatics 30(9): 1312-1313. https://doi.org/10.1093/bioinformatics/btu033

Stebbins, G. L. 1971. Chromosomal Evolution in Higher Plants. Edward Arnold, London.

Taberlet, P., L. Gielly, G. Pautou \& J. Bouvet. 1991. Universal primers for amplification of three non-coding regions of chloroplast DNA. Pl. Molec. Biol. 17: 1105-1109. https:// doi.org/10.1007/BF00037152 
te Beest, M., J. J. Le Roux, D. M. Richardson, A. K. Brysting, J. Suda, M. Kubesova \& P. Pysek. 2012. The more the better? The role of polyploidy in facilitating plant invasions. Ann. Bot. 109: 19-45. https://doi.org/10.1093/aob/mcr277

Thomas, B. R., V. S. Ford, E. Pichersky \& L. D. Gottlieb. 1993. Molecular characterization of duplicate cytosolic phosphoglucose isomerase genes in Clarkia and comparison to the single gene in Arabidopsis. Genetics 135: 895-905.

Tiffney, B. H. 1985. Perspectives on the origin of the floristic similarity between eastern Asia and eastern North America. J. Arnold Arbor. 66: 73-94.

Tiffney, B. H. \& S. R. Manchester. 2001. The use of geological and paleontological evidence in evaluating plant phylogenetic hypotheses in the Northern Hemisphere Tertiary. Int. J. Pl. Sci. 162: S3-S17.

Tobe, H., P. H. Raven \& C.-I Peng. 1988. Seed coat anatomy and relationships of Ludwigia sect. Microcarpium, Dantia and Miquelia (Onagraceae), and notes on fossil seeds of Ludwigia from Europe. Bot. Gaz. 149: 450-457.

Valcárcel, V. \& J. Wen. 2019. Chloroplast phylogenomic data support Eocene amphi-Pacific early radiation for the Asian
Palmate core Araliaceae. J. Syst. Evol. 57(6): 547-560. https://doi.org/10.1111/jse.12522

Wagner, W. H. 1954. Reticulate evolution in the Appalachian Aspleniums. Evolution 8: 103-118. https://doi.org/10.1111/ j.1558-5646.1954.tb00117.x

Wagner, W. L., P. C. Hoch \& P. H. Raven. 2007. Revised classification of the Onagraceae. Syst. Bot. Monogr. 83: 1-240.

Wen, J., Z. L. Nie \& S. M. Ickert-Bond. 2016. Intercontinental disjunctions between eastern Asia and western North America in vascular plants highlight the biogeographic importance of the Bering land bridge from late Cretaceous to Neogene. J. Syst. Evol. 54: 469-490. https://doi.org/10.1111/jse.12222

White, D. M., M. B. Islam \& R. J. Mason-Gamer. 2019. Phylogenetic inference in section Archerythroxylum informs taxonomy, biogeography, and the domestication of coca (Erythroxylum species). Amer. J. Bot. 106(1): 154-165. https:// doi.org/10.1002/ajb2.1224

Zhang, Q., Y. Liu \& Sodmergen. 2003. Examination of the cytoplasmic DNA in male reproductive cells to determine the potential for cytoplasmic inheritance in 295 angiosperm species. Pl. Cell Physiol. 44: 941-951. https://doi.org/ 10.1093/pcp/pcg121 